\title{
The Natural History of the Silver-Russell Syndrome: A Longitudinal Study of Thirty-nine Cases
}

\author{
J. M. TANNER, ${ }^{(57)}$ H. LEJARRAGA, AND N. CAMERON \\ Department of Growth and Development, Institute of Child Health, University of London, and The Hospital for Sick \\ Children, London, England
}

Extract

The growth of 39 children with Silver-Russell syndrome has been followed for 1-13 years. Pregnancy and labor were normal; none of the 61 sibs had the syndrome. Height at referral (mean age 4.6 years) averaged 3.6 SD below the mean and remained at this level during subsequent growth. Bone age averaged $69 \%$ of normal at referral but caught up by puberty, which occurred at the normal time. Nineteen cases were treated with human growth hormone without lasting effect. There is no clear-cut distinction between the Silver and Russell syndromes; the name should be Silver-Russell. It is likely that some $10 \%$ of cases have birth weights in the -1.5 to -2.0 SD range.

\section{Speculation}

A detailed longitudinal study of the growth and development of children with the syndromes of Silver and Russell reveals a characteristic growth curve, very little affected by administration of growth hormone; a normal, not advanced, puberty; and a poor outcome.

Among children brought to the physician because of short stature there are a number who have a low birth weight for length of gestation. Some of these have recognizable syndromes, such as Turner's, congenital rubella, and de Lange's. Others, often equally recognizable, are short, thin (in the sense of lacking subcutaneous fat), and apparently healthy. They have a characteristic appearance; the face is triangular and small, the ears appear to be set low, the corners of the mouth are frequently turned downwards, and the mandible is small in relation to the maxilla. The fifth fingers are usually short and curved inwards. Although the relation of trunk to limbs is normal, in some of these patients the limbs, trunk, or face show a degree of asymmetry which exceeds the usual limits.

These children were first recognized by Silver et al. (37) in 1953, who described two cases, both with characteristic asymmetry. Independently, Russell (33) in 1954 described five similar children of whom only two had asymmetry. In the subsequent literature some authors have separated the cases with asymmetry (Silver's syndrome) from those without it (Russell's syndrome, Russell's intrauterine dwarfism), whereas others have combined them. For reasons discussed below we have placed symmetrical and asymmetrical cases together under the name Silver-Russell syndrome.

We have studied longitudinally the growth of 39 children with this. syndrome, measuring them at regular intervals for periods between 1 and 13 years. Nineteen have been treated for 1 or more years with human growth hormone. In addition, we have reviewed 66 cases reported in the literature up to the end of 1972. (This number excludes those reported by Tanner and Ham (44), which form part of the present series.)

\section{SUBJECTS AND METHODS}

Among all children referred to the Growth Disorder Clinic of The Hospital for Sick Children between 1960 and 1974 were 22 boys and 17 girls who satisfied the following three criteria: (I) stature 2 SD or more below the 50th percentile for height on the British standards (49); (2) birthweight adjusted for sex, length of gestation, birth order, and maternal height $2 \mathrm{SD}$ or more below the 50th percentile on the Tanner-Thomson (45) standards; (3) absence of a recognizable syndrome such as de Lange's and of chromosomal, endocrine, metabolic, chondrodystrophic, or psychiatric disturbance which would account for the short stature.

Body measurements were made at regular intervals following the techniques described previously $(43,47)$. Triceps and subscapular skinfolds were measured with Harpenden calipers (46). In addition, photogrammetric photographs (12) were made on each occasion and limb measurements taken from these (23). Upper limb length (shoulder-wrist) was taken on the front view photograph from the lateral end of the clavicle to the base of the thenar eminence at the distal skin crease of the wrist. Lower limb length (gluteal fold-ankle) was taken from the rear view photograph from a horizontal line drawn through the intersection of the medial end of the gluteal fold with the medial border of the thigh to the most prominent part of the outline of the lateral malleolus. Bone ages were determined from radiographs of the left hand and wrist according to the revised Tanner-Whitehouse method using radius, ulna, metacarpals, and phalanges only (the RUS score) (48).

Standard deviation scores (SD scores) for height and other measurements have been used to allow for age and sex differences. They were computed by:

$$
\text { SD score }=(X-\bar{x}) / s_{\mathbf{x}} .
$$

where $X$ is the measurement, $\bar{x}$ the mean of the measurements of the standardizing group for the age in question, and $s_{x}$ the SD of the group. In a normally distributed sample, the SD score has a mean of 0 and an SD of 1 . Because of the adolescent spurt, height SD scores at ages $10-16$ in girls and $12-18$ in boys do not have the simple interpretation valid for other ages, and have not been included here.

Birth weights are given as adjusted for sex, length of gestation, and birth order and, in certain calculations, additionally for maternal height (45). The adjustment was to male, 40 weeks of gestation and laterborn. In practice we used a computer program, but close approximation can be achieved by finding on the Tanner-Thomson charts (45) the birth weight at 40 weeks corresponding to the percentile for the infants' actual birth weight, adding $180 \mathrm{~g}$ if it is a girl, and a further $130 \mathrm{~g}$ if it is firstborn. Adjustment for maternal height was made to a standard height of $162.0 \mathrm{~cm}$. These calculations lead to a SD score for adjusted birth weight in relation to a standard population, that of Aberdeen infants. 
Nineteen patients were treated with human growth hormone (HGH), 18 at $10 \mathrm{IU}$ and one at 5 IU twice weekly as part of the Clinical Trial organized by the Medical Research Council Working Party on Human Growth Hormone, to whom we are grateful for supplies. Details of the preparation used have been given elsewhere (47).

\section{RESULTS}

\section{OBSTETRIC DATA}

Course of Pregnancy. In 21 of the 39 cases obstetric data were obtained from the hospital where the child was born; in 18 the history depended on the mother's recollection. The course of the pregnancy was normal in 27 cases. There were two cases of threatened abortion, two of placenta previa, one of maternal tuberculosis and four of maternal hypertension or pre-eclampsia. None of these conditions are thought in themselves to cause low birth weight (28).

We have examined the pregnancy data in the 66 cases reported to the end of $1972(3,8,10,13,14,16-22,27,29-35,37-40,53)$. In these also there is little indication of a greater than usual (7) incidence of maternal pathology. In particular, there were only two cases of pre-eclampsia, so the combined incidence was $6 \%$, compared with the Perinatal Mortality Survey (7) figure of $9 \%$.

Labor. Labor was said to be normal in 29 of our 39 cases. In one it was prolonged, in two precipitate; there were two cesarean sections, one because of fetal distress, the other because of placenta previa; two breech deliveries; and two retained placentas. Both breech deliveries were unassisted and the infants had a normal neonatal course.

Neonatal Period. The neonatal period was uneventful in 29 cases but 10 children had either cyanosis at birth, a low apgar score, neonatal jaundice, or feeding problems during the first few days. Three of these had to be kept in the premature unit, two for a few days only but one for 6 weeks.

There were no statistically significant differences in incidence of abnormality in pregnancy, labor, or neonatal course between the 16 cases with asymmetry (Silver) and the 23 cases without it (Russell). There were no differences either between the obstetric histories of those children who subsequently showed some degree of catch-up in height (see below) and those who did not.

Maternal Age. Maternal age at the child's birth was known in 22 cases. The mean was $26.7 \pm 1.03$ years. For comparison, the mothers of 10 children with isolated growth hormone deficiency attending the same clinic had a mean age of $28.3 \pm 1.6$ years, and mothers of those attending with other diagnoses a mean age of 27.4 \pm 1.5 years. The correlation coefficient between maternal age and adjusted birth weight in the Silver-Russell patients was not significantly different from 0 .

Birth Order. The birth orders of the Silver-Russell cases were not strikingly different from those of the normal population (6). Orders $1,2,3$, and 4 were represented by $33 \%, 49 \%, 13 \%$, and $5 \%$; the normal population percentages are $37 \%, 31 \%, 16 \%$, and $8 \%$.

In summary, there is little to suggest that any of the common abnormalities of pregnancy or labor are responsible for the reduced growth of these children.

\section{BIRTH WEIGHT}

The birth weights of the available previously reported cases and the 39 present ones are plotted in Figure 1 on the Tanner-Thomson standards (without adjustments for birth order or maternal size).

Gestational Age. Gestational age (as recorded by the obstetrician) was within normal limits for all except four children in our series (each born at 36 weeks) and three in the literature, a total preterm incidence of $7 \%$ which does not differ significantly from the normal population (5.3\% in the Perinatal Mortality Survey). The average gestational age of the 39 cases was 39.7 weeks.

Birth Weight SD Score. Figure 2 shows (on the left) the distribution of the birth weight SD score, adjusted to male, 40 weeks of gestation, and laterborn as described in Methods. The distribution might be regarded as Gaussian, with its right-hand side truncated by the sampling criterion. (The one case not reaching 2 SD below the mean did so when further adjusted for maternal height.) Supposing it really is so, we might estimate that our admittedly arbitrary criterion has cut off about $10 \%$ of cases. The implications of this are further considered in the Discussion.

The mean birth weights, unadjusted and adjusted, and the SD score of adjusted birth weight are given in Table 1. The unadjusted mean was $1.90 \pm 0.06 \mathrm{~kg}$, reducing to $1.87 \pm 0.06 \mathrm{~kg}$ on adjustment. The SD score mean was $-3.09 \mathrm{U}$. The lowest value for adjusted birth weight SD score was -4.8 . The birth weights of the literature cases, if all are adjusted as though laterborn and with mothers of average height (the information is frequently missing). have a mean SD score of $-3.27 \pm 0.06$, with a SD of 0.46 units.

There was no significant difference between birth weights of symmetrical and asymmetrical patients (Table 1).

\section{BIRTH WEIGHT OF SIBLINGS}

None of the sibs of our patients were of small stature. Birth weights were known for 61 sibs of 34 patients. The birth weights adjusted for sex, gestation, and birth order are plotted in Figure 2.

The average birth weight was $3.18 \pm 0.06 \mathrm{~kg}$, which on adjustment became $3.28 \mathrm{~kg}$ (Table 1). The mean SD score was $-0.47 \pm 0.11 \mathrm{U}$ when maternal height was also allowed for (the mothers being a little smaller than the criterion height). Although this value is significantly below the mean of the standards this probably reflects the rather high level of the Aberdeen standards which came from children with near optimal care. A truer comparison may be with the Perinatal Mortality Survey (7) values, representing the whole UK. These give a mean (unadjusted) of 3.32 $\mathrm{kg}$ which is insignificantly different from the unadjusted mean of the siblings. The spread of the sib distribution was similar to that of the general population. Only two sibs $(3 \%)$ were at or below -2 SD (Fig. 2), and this is not significantly different from expectation in a Gaussian distribution.

In summary, gestational age of these patients was normal: intrauterine growth failure did not occur in any of the siblings, who entirely resembled the normal population; mothers' heights were within normal limits. It seems quite possible that some $10 \%$ of the patients who have Silver-Russell syndrome, although in its mildest form, would be found with birth weights between -1.5 and -2.0 SD.

\section{HEIGHT AND BONE AGES AT REFERRAL}

Table 2 shows the height (or supine length at ages under 2.0 years), height SD score, bone age SD score, and height for bone age $\mathrm{SD}$ score at first referral. (Cases 6, 7, 9, 13, 15, 20, 24, 26.31, $32,36,37,38$, and 39 were those reported in part previously by Tanner and colleagues (47) and cases $7,9,26,31$, and 38 were included in the study of Tanner and Ham (44).)

The average age at referral was 4.6 years, with a range of $1.4-10.3$ years. Bone age was retarded in 34 of the 39 cases (last column, Table 3 ). The absolute retardation was greater in older children; in those aged $1.4-2.99$ it averaged 0.77 years and in those aged $3.0-7.99,1.59$ years. Thus the bone age in percentage of chronologic age was approximately the same $(69 \%)$ at all ages of referral.

The height SD score averaged -3.58 and ranged from -2.2 to -6.3 . The bone age SD score averaged -1.59 . Thirteen cases (i.e., $33 \%$ ) had a bone age SD score of less than -2 and hence would have been classified as abnormally retarded.

\section{GROWTH IN HEIGHT AND BONE AGE}

The 39 children have been followed regularly for periods between 1.2 and 12.7 years at the time of writing. The mean follow-up period was 6.4 years. The height and height velocity 

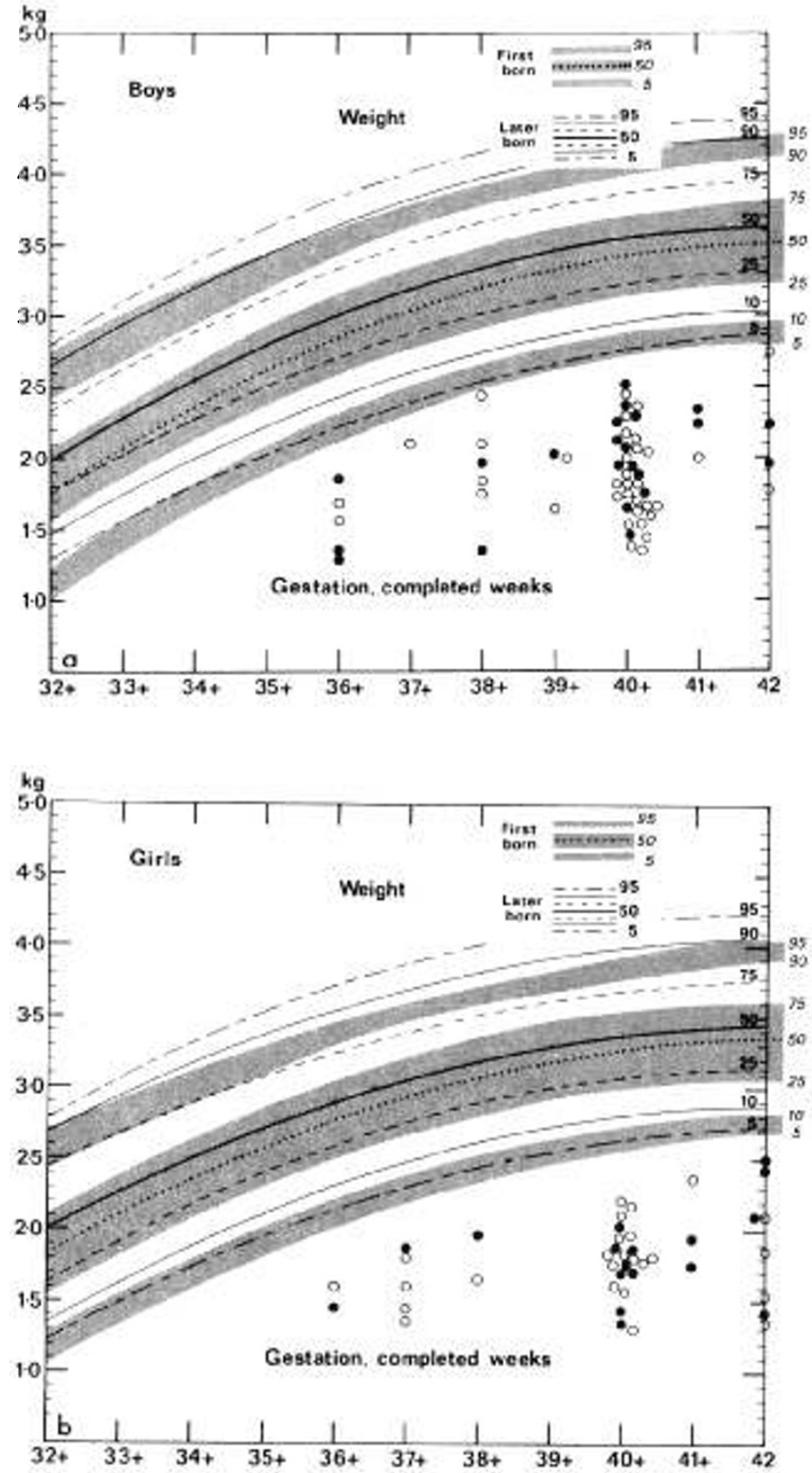

Fig. 1. Birth weights of previously reported $(O)$ and present sample $(\bullet$ of Silver-Russell cases, plotted on Tanner-Thomson standard (45). (No allowance for mothers height or birth order.) Chart prepared by J. M. Tanner and R. H. Whitehouse, Institute of Child Health, University of London, from data of Thomson et al. (51).

curves of a representative case are shown in Figure 3. The height for bone age is marked by stars; thus the retardation of bone age is given by the lengths of the dashed horizontal lines (-- ). Approximately the same percentile position is maintained during growth. The adolescent growth spurt is normal in shape and timing. although small. The first period of $\mathrm{HGH}$ administration merely coincides with the spurt, as the second period demonstrates.

Figures 4 and 5 show the height curves for 22 boys and 17 girls. The broken portions of the lines represent periods of treatment with $\mathrm{HGH}$. Evidently the majority of the patients, like the girl shown in Figure 3, remained at about the same position below the 3 rd percentile during their whole term of growth.

This impression is reinforced by Figure 6 , which shows the average height SD score at each year of age. (In this and the following graphs heights at a given age, e.g., 5.0 years, have been obtained by graphic interpolation from individual growth curves.) The SD score remained between -3.3 and -3.0 from age 3 to 13 years.

The velocity of height growth is shown in Figures 7 and 8. Yearly periods only are plotted, since the standards are based on measurements at annual intervals and the percentiles would be wider if periods of less than a year were considered (50). The height velocity was practically always within normal limits (in sharp distinction to the situation in growth hormone deficiency, for example) but on average ran at about the 25 th-35th percentile. (The situation at puberty will be discussed below.)

The bone age SD score is shown in Figure 9. There was a gradual increase from age 3 to 13. Thus the bone age approached closer to normality as the children got older, and by the beginning of puberty was on average only 6 months retarded. At this time a few children actually had a bone age in advance of chronologic age.

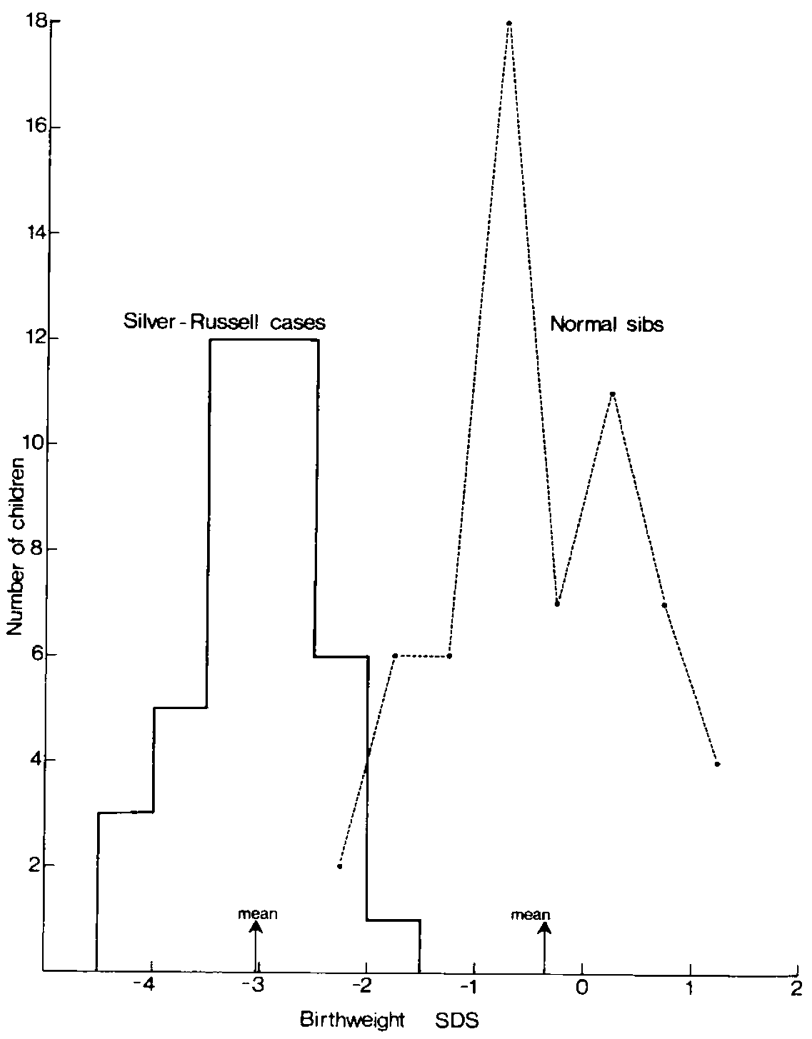

Fig. 2. Distributions of birth weight SD scores of Silver-Russell patients (adjusted for sex, gestational age and birth order) and distributions of birth weight SD scores of siblings of Silver-Russell patients (adjusted for sex, gestational age, and birth order).

Table 1. Birth weights of 39 Silver-Russell cases and their 61 siblings

\begin{tabular}{|c|c|c|c|c|}
\hline & \multicolumn{2}{|c|}{$\begin{array}{l}\text { Silver-Russell } \\
\text { cases }\end{array}$} & \multicolumn{2}{|l|}{ Siblings } \\
\hline & Mean $\pm \mathrm{SE}$ & $\mathrm{SD}$ & Mean $\pm \mathrm{SE}$ & $\mathrm{SD}$ \\
\hline $\begin{array}{l}\text { Birth weight }(\mathrm{kg}) \\
\text { unadjusted }\end{array}$ & $1.90 \pm 0.06$ & 0.34 & $3.18 \pm 0.06$ & 0.48 \\
\hline $\begin{array}{l}\text { Birth weight }(\mathrm{kg}) \\
\text { adjusted for sex, } \\
\text { gestational age, } \\
\text { birth order, and } \\
\text { maternal height }\end{array}$ & $1.87 \pm 0.06$ & 0.38 & $3.28 \pm 0.06$ & 0.48 \\
\hline $\begin{array}{l}\text { Birth weight SD score } \\
\text { (adjusted) }\end{array}$ & $-3.09 \pm 0.12$ & 0.68 & $-0.47 \pm 0.11$ & 0.86 \\
\hline
\end{tabular}


Table 2. Values at referral for 39 children with Silver-Russell sindrome

\begin{tabular}{|c|c|c|c|c|c|c|c|c|}
\hline Case & Sex & $\begin{array}{c}\text { Chronological } \\
\text { age, yr }\end{array}$ & Bone age, yr & $\begin{array}{l}\text { Height } \\
\mathrm{cm}\end{array}$ & $\begin{array}{l}\text { Height, } \\
\text { SD score }\end{array}$ & $\begin{array}{l}\text { Bone age, } \\
\text { SD score }\end{array}$ & $\begin{array}{l}\text { Height for } \\
\text { bone age, } \\
\text { SD score }\end{array}$ & $\begin{array}{c}\text { Chronological } \\
\text { age less } \\
\text { bone age, yr }\end{array}$ \\
\hline 1 & $\mathrm{~F}$ & 1.40 & 0.78 & 62.0 & -5.9 & -1.89 & -3.4 & 0.62 \\
\hline 2 & $\mathrm{M}$ & 1.57 & 1.78 & 69.9 & -4.2 & 0.57 & -4.7 & -0.21 \\
\hline 3 & $\mathrm{~F}$ & 1.57 & 1.24 & 72.7 & -2.8 & -0.90 & -1.7 & 0.33 \\
\hline 4 & $\mathrm{M}$ & 1.60 & 0.22 & 71.7 & -3.7 & -3.69 & 3.9 & 1.38 \\
\hline 5 & $\mathrm{~F}$ & 1.61 & 0.91 & 64.7 & -5.5 & -1.86 & -3.1 & 0.70 \\
\hline 6 & $\mathrm{~F}$ & 1.80 & 1.03 & 63.8 & -6.3 & -1.83 & -4.0 & 0.77 \\
\hline 7 & $\mathrm{~F}$ & 1.82 & 2.11 & 72.5 & -3.5 & 0.68 & -3.9 & -0.29 \\
\hline 8 & $\mathrm{~F}$ & 2.40 & 2.28 & 80.2 & -2.2 & -0.22 & -2.0 & 0.12 \\
\hline 9 & $\mathrm{M}$ & 2.43 & 0.22 & 76.7 & -3.6 & -4.12 & 8.0 & 2.21 \\
\hline 10 & $\mathrm{~F}$ & 2.48 & 2.10 & 76.8 & -3.3 & -0.71 & -2.6 & 0.38 \\
\hline 11 & $\mathrm{~F}$ & 2.53 & 1.68 & 77.2 & -3.3 & -1.54 & -1.7 & 0.85 \\
\hline 12 & $\mathrm{~F}$ & 2.65 & 1.22 & 82.0 & -2.2 & -2.50 & 1.7 & 1.43 \\
\hline 13 & $\mathrm{M}$ & 2.95 & 0.40 & 79.9 & -3.7 & -4.14 & 6.5 & 2.55 \\
\hline 14 & $\mathbf{M}$ & 2.96 & 3.00 & 84.2 & -2.6 & 0.02 & -2.6 & -0.01 \\
\hline 15 & $\mathrm{~F}$ & 3.03 & 1.65 & 78.5 & -3.8 & -2.19 & -1.2 & 1.39 \\
\hline 16 & $\mathbf{M}$ & 3.07 & 2.10 & 81.6 & -3.4 & -1.52 & -1.5 & 0.97 \\
\hline 17 & $\mathrm{~F}$ & 3.47 & 3.07 & 86.5 & -2.5 & -0.54 & -1.8 & 0.40 \\
\hline 18 & $\mathrm{M}$ & 3.57 & 2.28 & 82.4 & -3.9 & -1.70 & -1.7 & 1.29 \\
\hline 19 & $\mathrm{M}$ & 3.75 & 2.30 & 84.7 & -3.6 & -1.81 & -1.1 & 1.45 \\
\hline 20 & $\mathrm{M}$ & 3.93 & 2.53 & 90.1 & -2.6 & -1.66 & -0.1 & 1.40 \\
\hline 21 & $\mathrm{M}$ & 4.22 & 2.07 & 88.7 & -3.3 & -2.46 & 0.7 & 2.15 \\
\hline 22 & $\mathrm{M}$ & 4.89 & 3.84 & 88.1 & -4.1 & -1.13 & -2.9 & 1.05 \\
\hline 23 & $\mathbf{M}$ & 4.95 & 2.06 & 92.6 & -3.3 & -3.11 & 1.9 & 2.90 \\
\hline 24 & $\mathbf{M}$ & 4.99 & 2.92 & 87.5 & -4.4 & -2.22 & -1.6 & 2.08 \\
\hline 25 & $\mathrm{M}$ & 5.21 & 2.10 & 89.0 & -4.3 & -3.27 & 0.7 & 3.11 \\
\hline 26 & $\mathbf{M}$ & 5.27 & 3.73 & 93.7 & -3.4 & -1.61 & -1.1 & 1.54 \\
\hline 27 & $F$ & 5.58 & 2.28 & 92.3 & -3.9 & -3.36 & 1.5 & 3.30 \\
\hline 28 & $\mathrm{M}$ & 5.62 & 4.32 & 94.8 & -3.5 & -1.32 & -2.0 & 1.30 \\
\hline 29 & $\mathbf{M}$ & 5.69 & 4.39 & 93.8 & -3.8 & -1.31 & -2.3 & 1.30 \\
\hline 30 & $\mathrm{~F}$ & 5.75 & 4.72 & 94.0 & -3.8 & -1.04 & -2.6 & 1.03 \\
\hline 31 & $\mathrm{~F}$ & 5.91 & 2.92 & 94.5 & -3.8 & -2.97 & 0.6 & 2.99 \\
\hline 32 & $\mathrm{~F}$ & 6.37 & 7.05 & 99.5 & -3.3 & 0.67 & -3.9 & -0.68 \\
\hline 33 & $\mathrm{M}$ & 6.65 & 4.50 & 100.6 & -3.3 & -2.12 & -1.0 & 2.15 \\
\hline 34 & $\mathrm{M}$ & 7.74 & 7.14 & 109.6 & -2.7 & -0.59 & -2.1 & 0.59 \\
\hline 35 & $\mathrm{~F}$ & 8.99 & 8.04 & 115.7 & -2.5 & -0.93 & -1.7 & 0.95 \\
\hline 36 & $\mathbf{M}$ & 9.85 & 7.17 & 109.2 & -4.4 & -2.64 & -2.2 & 2.68 \\
\hline 37 & $\mathrm{M}$ & 10.04 & 10.59 & 119.0 & -2.9 & 0.54 & -3.3 & -0.55 \\
\hline 38 & $\mathrm{M}$ & 10.08 & 8.84 & 116.5 & -3.3 & -1.22 & -2.4 & 1.24 \\
\hline 39 & $\mathrm{M}$ & 10.29 & 9.79 & 119.9 & -3.0 & -0.49 & -2.6 & 0.50 \\
\hline
\end{tabular}

This greater tendency towards catching up in bone age compared with height reduces the expected ultimate mature height.

Those children who tended to catch up in height tended also to catch up in bone age; the correlation between gain in height SD score from first referral to age 10 and gain in bone age SD score over the same period was 0.70 .

\section{PREDICTED ADULT HEIGHT}

Few of our patients have yet been followed to complete maturity. We have, therefore, used the equations of Tanner et al. (48) to predict their ultimate mature height. These equations were constructed from data on normal children so it is not certain that they apply to the Silver-Russell cases; however, we think they may, especially since bone age does not depart greatly from the normal range. Prediction from height and bone age at age 7 was possible in 10 boys and 10 girls. For boys the mean predicted adult height was $153.5 \mathrm{~cm}$ (SD score -3.2 ) and for girls $147.0 \mathrm{~cm}$ (SD score -2.5 ). This adult height would agree with the course of growth represented in Figure 6.

\section{GROWTH IN HEIGHT AT ADOLESCENCE}

Figures 7 and 8 show that the few cases studied during adolescence had a growth spurt well within normal limits (41), both as regards timing and peak velocity. The five peak velocities which we can estimate were all below the 50th percentile, so it seems that growth continued during this period at about the velocity percentile established before. The patient illustrated in Figure 10 shows an apparently typical pattern. Although his height approached the 3 rd percentile briefly because of his early spurt, he ended up at about the same percentile position he had at age 10 .

\section{EFFECT OF HUMAN GROWTH HORMONE ON HEIGHT GROWTH}

Twelve boys and seven girls were given intramuscular injections of $\mathrm{HGH}$ twice weekly (one at $5 \mathrm{IU} /$ injection, the remainder at 10 IU) over the period of a year. The results in some of these have been reported $(44,47)$; the follow-up of these cases has been extended, and five new cases added.

Twenty-one patients had serial estimations of plasma growth 

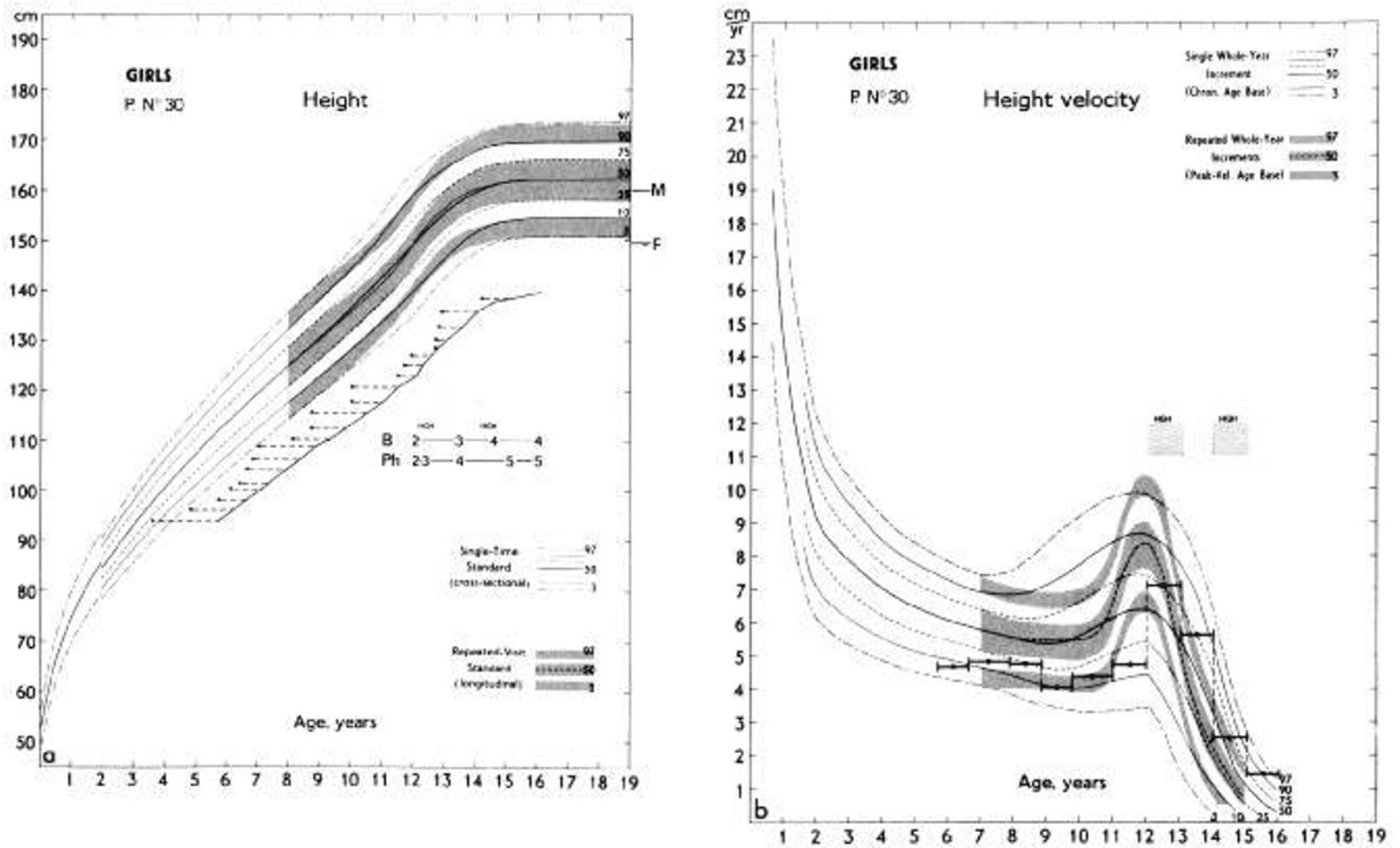

Fig. 3. Height (left) and height velocity (right) curves of a representative case of Silver-Russell syndrome. The stars in the left-hand figure represent the height plotted against bone age; ---, bone age retardation. Yearly velocities are plotted in the right-hand figure. Periods of human growth hormone $(H G H)$ administration and puberty ratings are indicated.

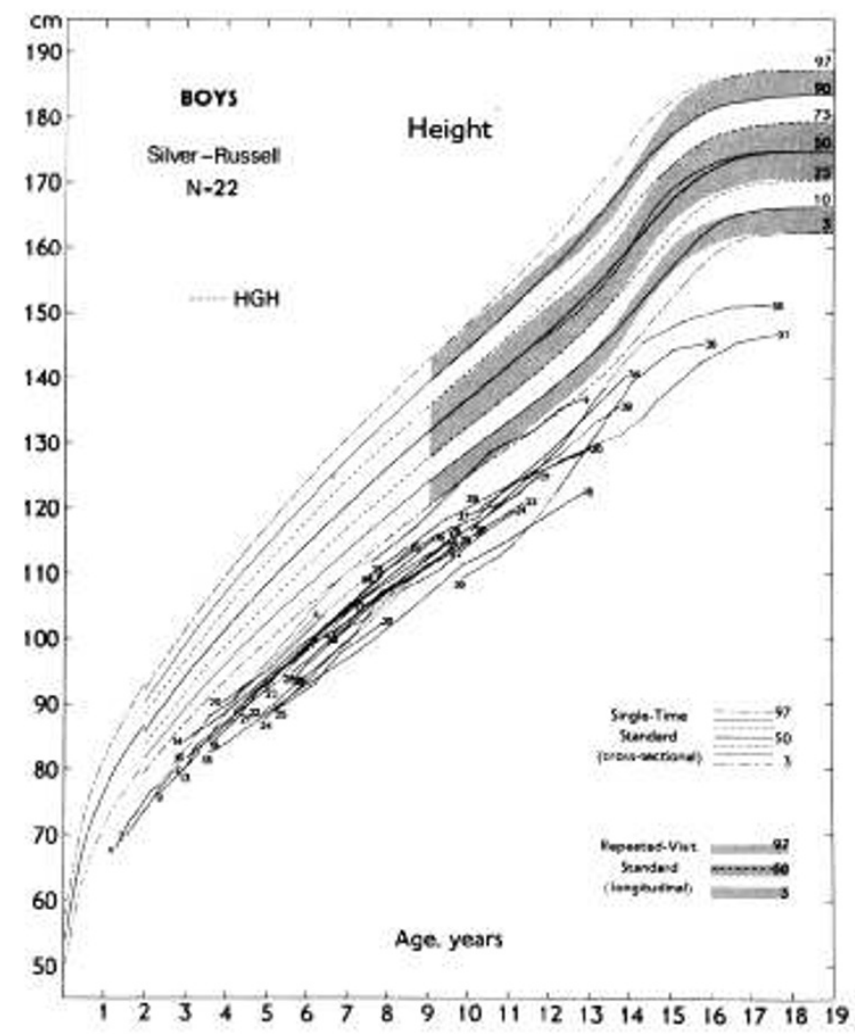

Fig. 4. Height curves for 22 boys with Silver-Russell syndrome Interrupted portions of the curve represent periods of treatment with human growth hormone $(H G H)$.

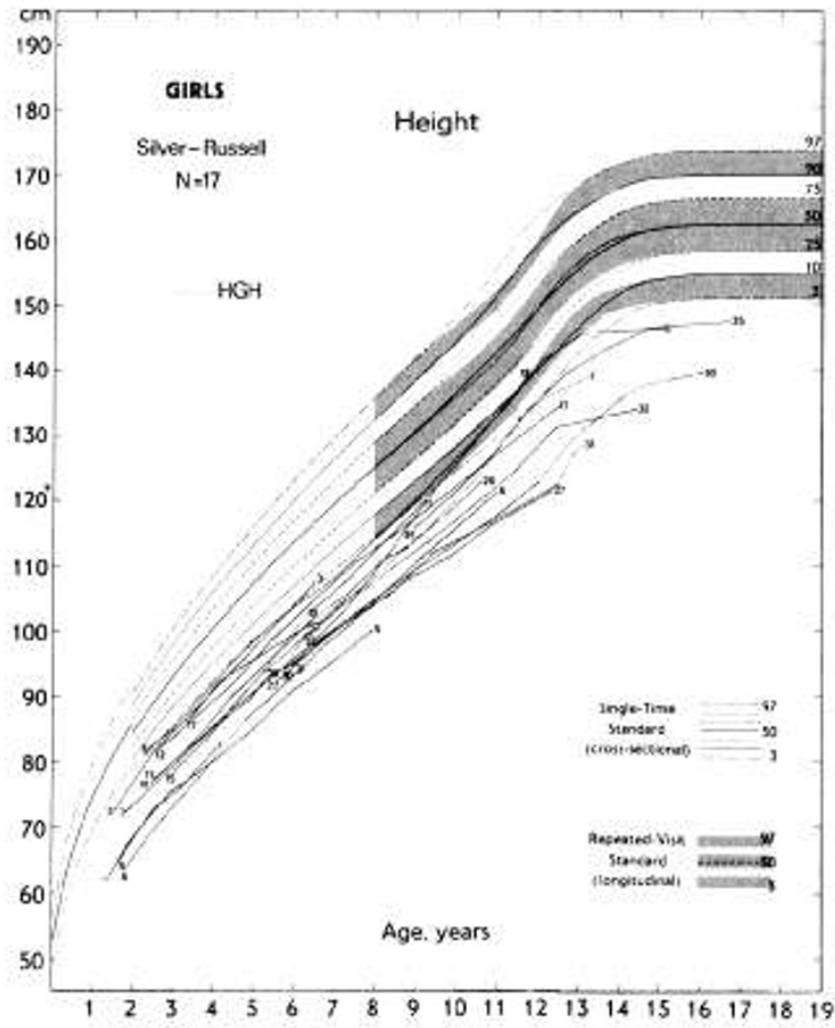

Fig. 5. Height curves of 17 girls with Silver-Russell syndrome. Interrupted portions of the curve represent periods of treatment with human growth hormone $(H G H)$. 


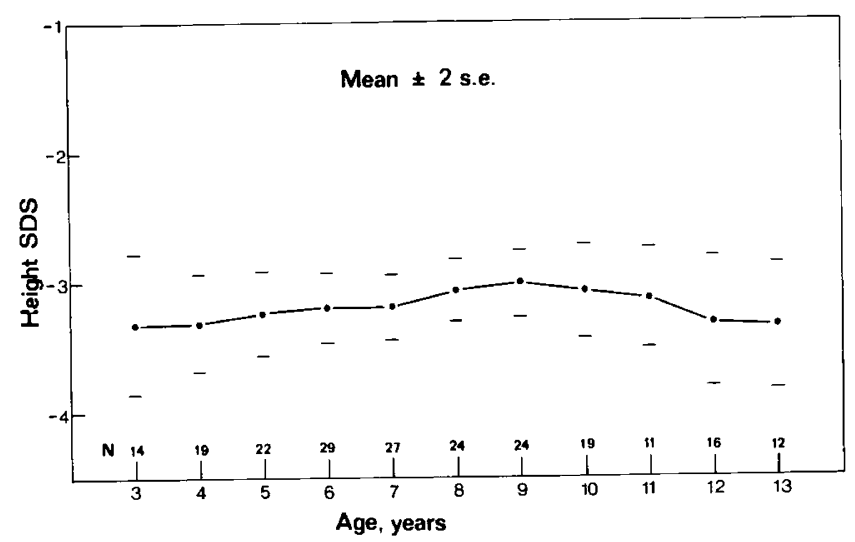

Fig. 6. Height SD scores $(S D S)$ at ages 3-13. Thirty-nine children, mixed longitudinal, numbers at each age as marked. Heights at exact years obtained by interpolation in individual growth curves.

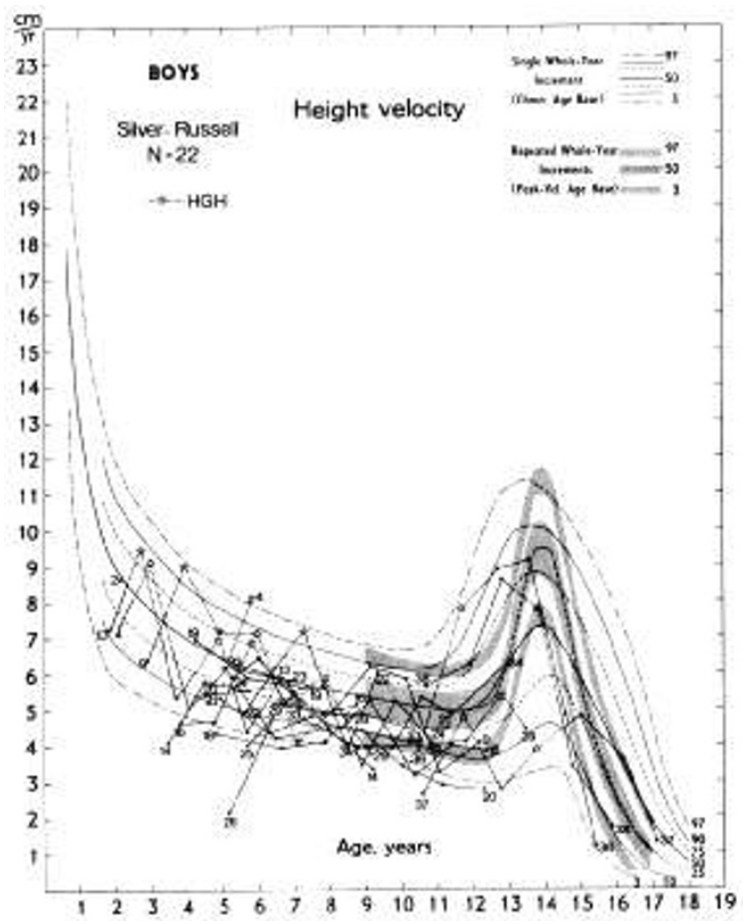

Fig. 7. Height velocity of 22 boys with Silver-Russell syndrome. Interrupted portions of curves represent periods of treatment with human growth hormone $(H G H)$.

hormone by radioimmunoassay after insulin-induced hypoglycemia. In twelve patients this was done before starting treatment, and in the others a year after treatment had ceased. All except one patient had normal peak values (above $20 \mu \mathrm{U} / \mathrm{ml}$ ) in hypoglycemia. The one exception had a hypoglycemic peak of 14 $\mu \mathrm{U}$ and a normal peak after Bovril. Most had peaks above $32 \mu \mathrm{U}$. Antibody levels of $\mathrm{HGH}$ were determined during treatment and in no case did more than a trivial level develop. insufficient to cause an effect on growth (9).

In Table 3 the height velocities in the pretreatment, treatment, and post-treatment years are given, together with the corresponding SD scores. The simple difference "treatment minus pretreatment" would underestimate the response to $\mathrm{HGH}$ since in untreated children a continuous deceleration occurs, the amount depending on age. This has to be allowed for in calculating a net gain due to treatment. Furthermore, it seems that in the post-treatment year, a "compensatory" slowing down of growth occurs, balancing wholly or partly the acceleration caused by treatment.

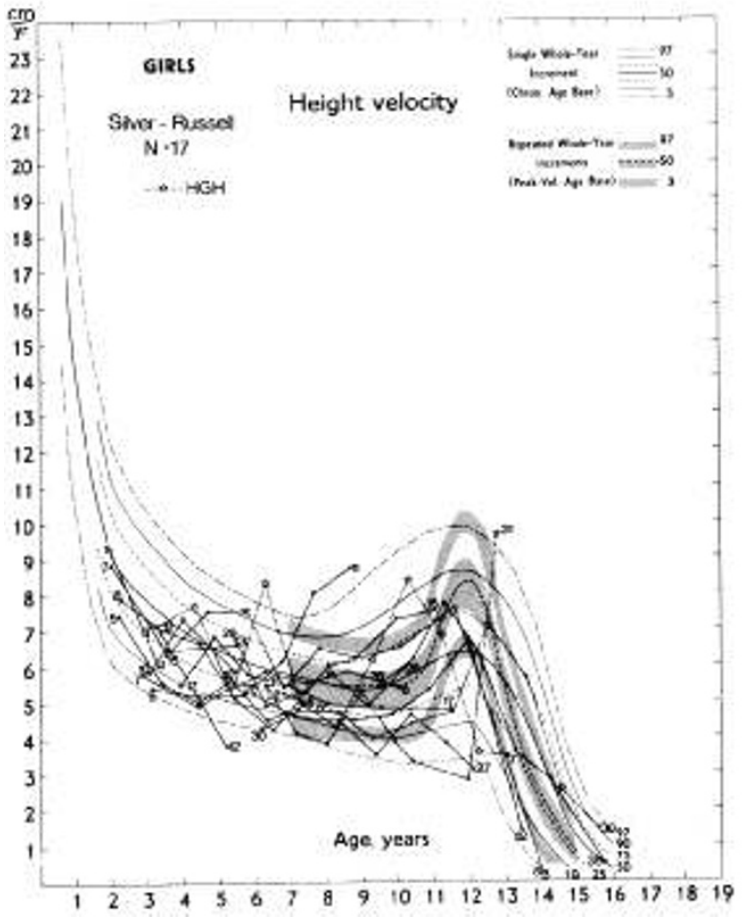

Fig. 8. Height velocity of 17 girls with Silver-Russell syndrome. Interrupted portions of curves represent periods of treatment with human growth hormone $(H G H)$.

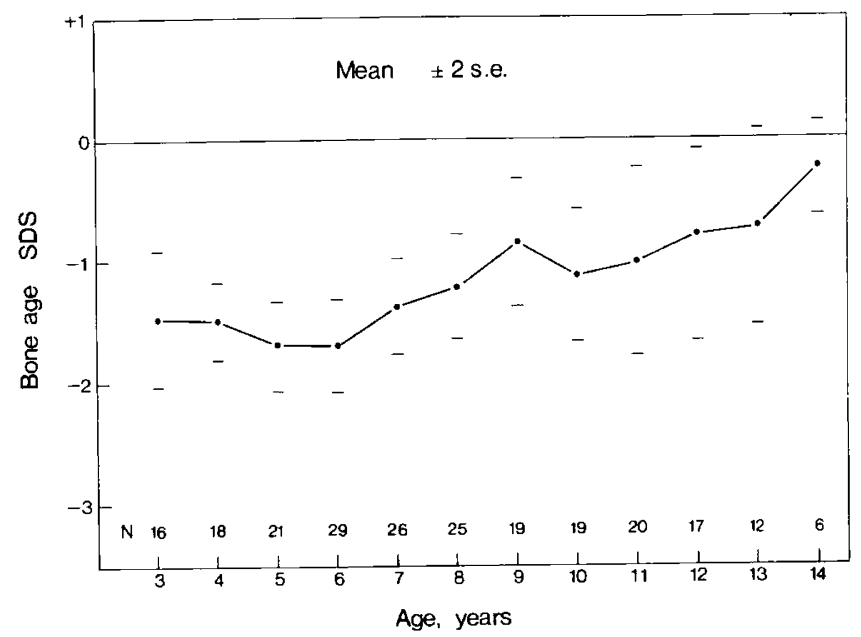

Fig. 9. Bone age SD scores (SDS) at ages 3-13 in Silver-Russell syndrome. Mean \pm 2 SE, 39 cases, mixed longitudinal with numbers of cases at each age as marked; both sexes.

Thus the 13 cases followed through all 3 years had mean velocity SD scores as follows: pretreatment -0.57 , treatment +0.63 , post-treatment -1.42 . This post-treatment slowing must also be allowed for. The estimated net gain from the treatment year is thus given by: net gain $=V_{T}-\left(V_{1}-D_{T}\right)+\left(V_{2}-V_{1}-D_{T}-D_{2}\right)=$ $V_{T}-2\left(V_{1}+D_{T}\right)+V_{2}-D_{2}$, where $V_{1}, V_{T}$, and $V_{2}$ are the velocities in the pretreatment, treatment, and post-treatment years, respectively; $D_{T}$ the expected normal deceleration during the treatment year (for a child growing, as these do, at $1 \mathrm{SD}$ below the mean velocity), and $D_{2}$ the expected deceleration during the posttreatment year. Values in parentheses in Table 3 signify that pubertal changes were present and because height velocities may then be complicated by the adolescent growth spurt, these values have been excluded from the calculation of the means.

The mean pretreatment velocity was $5.4 \mathrm{~cm} /$ year and the mean 
velocity on treatment was $6.8 \mathrm{~cm} /$ year. In the post-1reatment year the velocity fell to $4.6 \mathrm{~cm} /$ year. The estimated net gains ranged from $-1.4 \mathrm{~cm}$ to $+3.5 \mathrm{~cm}$, with a mean of $0.53 \pm 0.52 \mathrm{~cm}$, insignificantly greater than 0 .

We can use a second method to estimate the net treatment

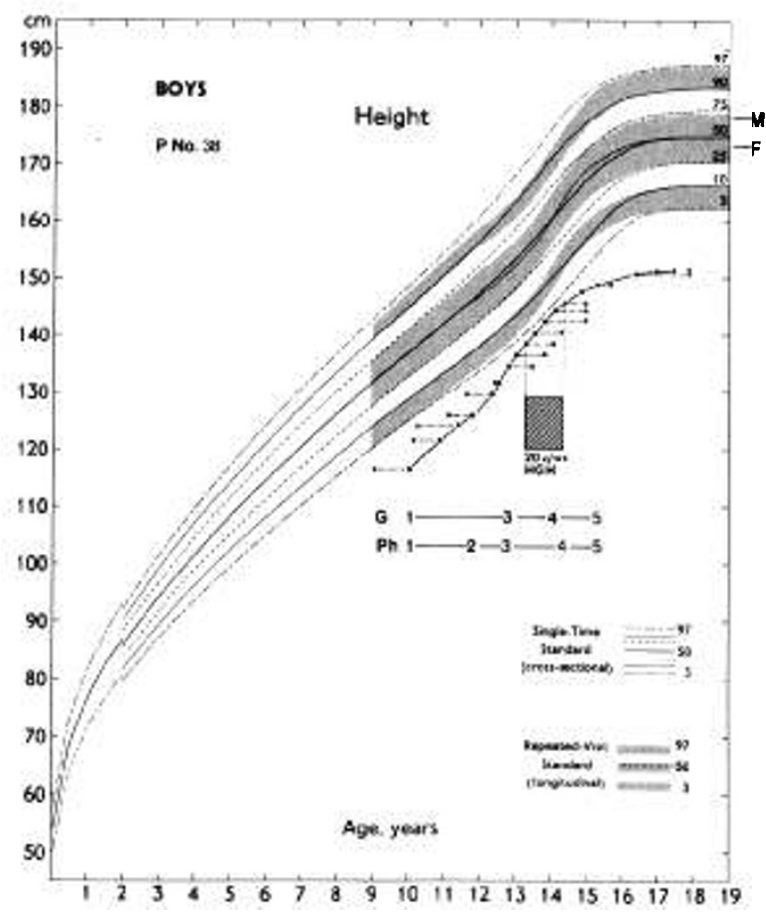

Fig. 10. Height growth at adolescence of boy with Silver-Russell syndrome. $M$ and $F$ represent mother's and father's height percentiles. effect. If we calculate the height SD score for each child at the beginning of treatment (mean -3.6), at the end of treatment (mean -3.2 ), and at the end of the post-treatment year (mean -3.25) we find a gain of $0.35 \mathrm{SD}$ score, compared with a gain of $0.25 \mathrm{SD}$ score achieved over the same age range by those not treated. Thus the net gain was $0.1 \mathrm{SD}$ score or about $0.5 \mathrm{~cm}$. Bone age velocity was not altered by treatment, being $0.88,1.01$ respectively, and 1.11 "year"/year in pretreatment, treatment, and post-treatment years, in the 13 cases followed longitudinally.

Two things have to be said about this negative result; first that if may conceal heterogeneity in response, and second that it does not deal with continuous treatment over several years, eliminating the "compensatory" post-treatment year. As regards the former, two children showed in the first treatment year a response which was above the value of $2.0 \mathrm{~cm} /$ year/year acceleration, the limit of what occurs normally (47). However, further treatment of one of these had no obvious effect and the final height was much below the 3 rd percentile. In two cases only was $\mathrm{HGH}$ administered for more than a year, in one continuously and in the other in alternate years. In neither case was the net clinical effect very impressive.

Widths of bone, muscle, and fat in the upper arm and calf were measured radiographically (47) during the pretreatment, treatment, and post-treatment years in, respectively 7,13 , and 13 cases. There was litt?e indication of any significant effect of treatment on bone or fat widths, but muscle width appeared to be significantly increased in the treatment year in a number of cases. This aspect of treatment seems to merit further investigation.

\section{PUBERTY IN SILVER-RUSSELL SYNDROME}

An abnormal timing or pattern of puberty was originally reported by Silver et al. $(35,37)$ as one of the features of the syndrome. However, increased knowledge of the great variation to be seen in normal children has cast much doubt on these findings. Seventeen of the 39 patients showed signs of puberty. Seven were

Table 3. Pretreatment, treatment and post-treatment height velocities (centimeters per vear), height velocities SD scores, and estimated net gains (centimeters) for 19 patients treated for 1 vear with human growth hormone

\begin{tabular}{|c|c|c|c|c|c|c|c|c|}
\hline Case & $\begin{array}{c}\text { Age at } \\
\text { beginning of } \\
\text { treatment, } y r\end{array}$ & $\begin{array}{c}\text { Pre- } \\
\text { treatment } \\
\text { velocity }\end{array}$ & $\begin{array}{c}\text { Treatment } \\
\text { velocity }\end{array}$ & $\begin{array}{l}\text { Post- } \\
\text { treatment } \\
\text { velocity }\end{array}$ & $\begin{array}{c}\text { Height } \\
\text { velocity } \\
\text { SD score. } \\
\text { pretreatment }\end{array}$ & $\begin{array}{c}\text { Height } \\
\text { velocity } \\
\text { SD score, } \\
\text { treatment }\end{array}$ & $\begin{array}{c}\text { Height } \\
\text { velocity } \\
\text { SD score, } \\
\text { post- } \\
\text { treatment }\end{array}$ & $\begin{array}{l}\text { Estimated } \\
\text { net gain }\end{array}$ \\
\hline 4 & 2.58 & 7.38 & 9.06 & 5.03 & -0.94 & 0.83 & -1.73 & 0.08 \\
\hline 6 & 3.85 & 7.18 & 7.70 & 5.42 & -0.35 & 0.77 & -0.89 & -0.34 \\
\hline 7 & 5.84 & 5.53 & 8.33 & 5.02 & -0.77 & 2.53 & -0.84 & 3.09 \\
\hline 9 & 3.37 & 6.37 & 8.99 & & -1.18 & 1.66 & & \\
\hline 13 & 4.16 & 5.33 & 6.94 & 4.40 & -1.63 & 0.28 & -1.91 & 1.38 \\
\hline 15 & 5.25 & 7.56 & 7.53 & 5.42 & 0.80 & 1.37 & -0.52 & -1.37 \\
\hline 16 & 5.25 & 4.68 & 6.93 & 5.10 & -1.83 & 0.80 & -0.83 & 3.47 \\
\hline 20 & 6.40 & 5.52 & 5.61 & 4.61 & -0.68 & -0.25 & -1.24 & -0.22 \\
\hline 22 & 7.04 & 6.06 & 7.46 & 3.85 & 0.16 & 2.11 & -2.07 & 0.04 \\
\hline 24 & 7.39 & 5.50 & 5.88 & 3.44 & -0.36 & 0.39 & -2.53 & -1.08 \\
\hline 26 & 7.72 & 5.22 & 5.74 & 4.90 & -0.63 & 0.25 & -0.72 & 0.84 \\
\hline 29 & 7.39 & 5.34 & 5.80 & 3.79 & -0.66 & 0.30 & -2.05 & 0.60 \\
\hline 30 & 12.05 & $(4.71)$ & $(7.10)$ & $(5.64)$ & $(-2.62)$ & $(0.36)$ & $(2.11)$ & \\
\hline 31 & 8.36 & 3.88 & 5.35 & 3.94 & 0.29 & -0.17 & -1.85 & 0.81 \\
\hline 32 & 7.30 & 5.19 & 4.80 & 4.50 & -0.77 & -0.99 & -1.26 & -0.50 \\
\hline 36 & 11.15 & 3.90 & $(7.78)$ & $(8.88)$ & -1.72 & $(3.71)$ & $(3.02)$ & \\
\hline 37 & 11.25 & 2.64 & $(4.75)$ & $(2.65)$ & -3.35 & $(-0.32)$ & $(-3.61)$ & \\
\hline 38 & 13.33 & $(8.57)$ & $(7.73)$ & $(3.38)$ & $(2.29)$ & $(-1.4 !)$ & $(-3.41)$ & \\
\hline .39 & 12.28 & 4.16 & 5.33 & & -1.03 & -0.88 & & \\
\hline$\overline{\mathrm{x}}$ & & 5.38 & 6.76 & 4.57 & -0.87 & 0.60 & -1.42 & 0.53 \\
\hline SE & & 0.32 & 0.36 & 0.24 & 0.24 & 0.26 & 0.23 & 0.52 \\
\hline$N$ & & 17 & 15 & 13 & 17 & 15 & 13 & 13 \\
\hline
\end{tabular}

' Figures in brackets correspond to values during presence of pubertal development and are excluded in calculation of the means.

${ }^{2}$ Estimated net gain calculated allowing for normal expected deceleration. See text. 
boys, 10 were girls. In Figures 11 and 12 their pubertal stages are plotted. The stages were those described by Tanner $(41,43)$ and differ from those of some other authors in that ratings of genitalia $(\mathrm{G})$ and pubic hair $(\mathrm{PH})$ are made quite separately. The standards on which the cases are plotted are of ages appropriate to each stage of puberty. A rating, e.g., B2, represents the presumed first moment of its appearance: a stage, e.g., B2-B3 (labeled B2+), lasts from the moment of $\mathrm{B} 2$ to the moment of $\mathrm{B} 3$. In most situations it is impossible to know exactly when B2 occurred; all one knows is that the child is in stage B2+. The range given in the figures represents the central $95 \%$ of British children based on the Harpenden Growth Study series of Marshall and Tanner $(24,25)$ but is adjusted forward so that age of menarche in that group would correspond to that of the general UK population. Each age at which the child was observed is plotted successively.

Six of the seven boys were within normal limits for all $G$ and $P H$ ratings (and also for testicular volume, measured with the Prader orchidometer and related to the standard of Zachmann, Prader, and colleagues (54)). One was a little delayed. Eight of the 10

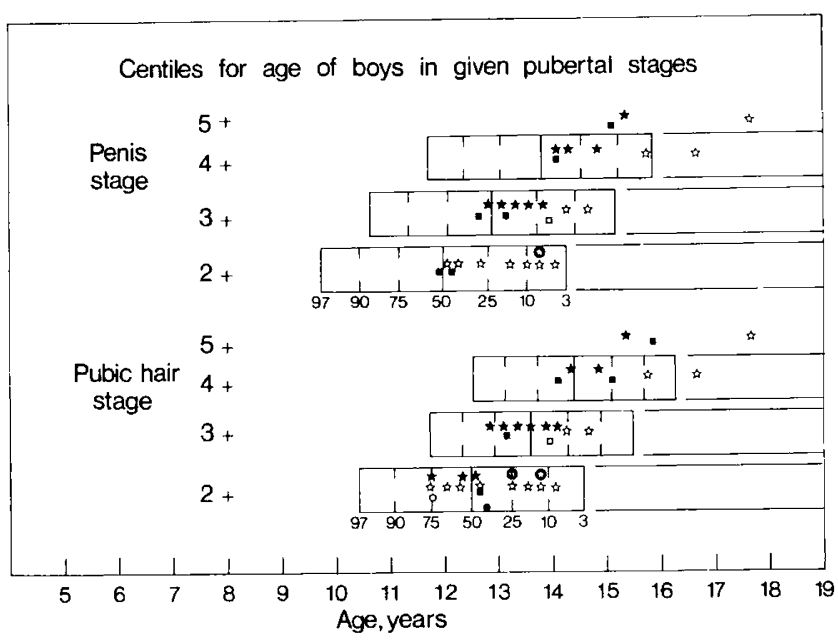

Fig. 11. Age at each stage of genitalia and pubic hair development in 7 boys with Silver-Russell syndrome compared with range of normal. Percentiles as indicated $(3,10$, etc.). Each set of symbols represents a different child.

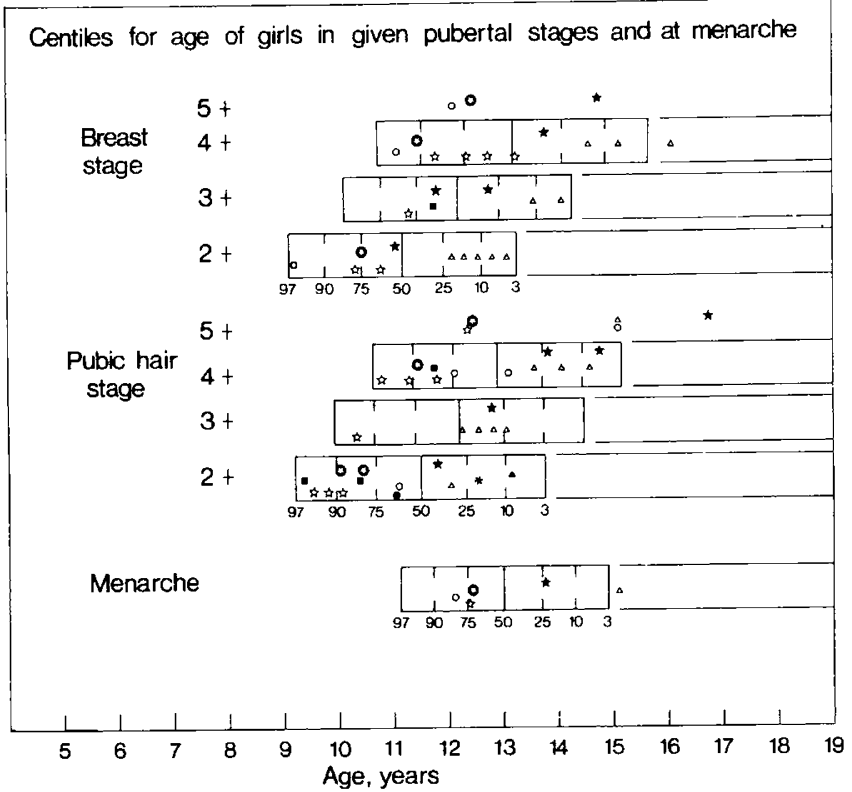

Fig. 12. Age at each stage of breast and pubic hair development and menarche in 10 girls with Silver-Russell syndrome, compared with range of normal. Percentiles as indicated $(3,10$, etc.). Each set of symbols represents a different child girls were within normal limits for the order of appearance and the duration of the various stages. One was slightly delayed and one (B2+ only plotted) slightly advanced (menarche 10.0 years, periods irregular until 11 years, pubic hair 90th percentile). There were no patients in the series who had reached an appropriate age for the first signs of puberty and failed to develop them.

LIMB ASYMMETRY IN NORMAL SUBJECTS AND SILVER-RUSSELL SYNDROME

Left and right upper and lower limbs were measured photogrammetrically in 61 healthy European boys and 45 girls aged 4-17 and $4-15$, respectively, belonging to the Harpenden Growth Study $(24,25,41)$. The mean and SD of the differences, left minus right, were calculated. As there was no discernible age trend, all ages were pooled. The mean difference did not differ significantly from 0 for lower limb length in both sexes and upper limb length in boys; in girls, however, the upper limbs of the right side averaged $0.31 \pm 0.07 \mathrm{~cm}$ more than those of the left. The SD of the differences, sexes pooled, were $0.49 \mathrm{~cm}$ for the upper limbs and $0.41 \mathrm{~cm}$ for the lower. (The measuring error is a little greater in the upper limb.) The approximate limits for the difference in length of the limbs measured in this way were $\pm 1 \mathrm{~cm}$.

Table 4 lists the degree of asymmetry in the 36 patients in whom it could be measured together with the clinical impression of whether the child was asymmetrical (Silver) or symmetrical (Russell). Differences above the $1 \mathrm{~cm}$ limit are given in italics. Perhaps surprisingly, there is total agreement between measurement and clinical impression. Twelve patients had significant asymmetry of one or both pairs of limbs. In seven patients the asymmetry was of the upper limb, in four patients of the lower limb, and in one patient of both limbs. One patient had a clinically noticeable asymmetry of trunk and face, although not of limbs.

The division into symmetric and asymmetric cases probably gives a false impression. When reflected about 0 so as to represent absolute differences, the distribution shows no bimodality but a steadily decreasing single tail. The difference between the groups lies rather in the spread of the patients' distribution. The SD of the arm differences was $0.9 \mathrm{~cm}$ in Silver-Russell patients compared with $0.5 \mathrm{~cm}$ in normal subjects and SD of leg differences was 1.3 $\mathrm{cm}$ compared with $0.4 \mathrm{~cm}$ in normal subjects. Apparently the process whereby bilateral symmetry is controlled is disturbed in patients with Silver-Russell syndrome.

\section{LIMB AND BODY PROPORTIONS}

A graph of upper limb length versus lower limb length in normal subjects was made, and the Silver-Russell patients' values plotted on it, average values of the two sides being taken. The patients' points fell within the range of the normal subjects so there seemed to be no general disturbance of upper-lower limb relationship. The only exception to this was a boy whose left leg was a full $6 \mathrm{~cm}$ longer than his right. His right leg was in proportion with his arms, suggesting he had hypertrophy of the left leg rather than hypoplasia of the right.

Russell (33) and later Tanner and Ham (44) thought that the arms were short compared with legs in these patients, but we have not confirmed this. The latter authors used stature minus sitting height as a measure of leg length and this is somewhat affected by the lack of fat on the butlocks (see below) giving extra apparent leg length. The present results seem to us more reliable.

Regression standards for sitting height on stature are used in our Growth Disorder Clinic for assessing the relation of trunk and limbs (42). The majority of the patients had a sitting height below the mean for stature, signifying relatively long limbs. All except one, however, were within normal limits. The SD score of sitting height for stature averaged $0.54 \pm 0.09 \mathrm{U}$ at the time of referral and changed little thereafter until puberty, when in the few cases available it tended to rise towards 0 . HGH treatment had no effect. This reduction in sitting height may be partly or wholly due to the unusually small amount of fat on the buttocks, rather than to skeletal differences from normal. However, case 31 , whose sitting 
Table 4. Differences in photogrammetic limb lengths (right minus left; centimeters) in Silver-R ussell syndrome ${ }^{1}$

\begin{tabular}{|c|c|c|c|c|}
\hline Case & Sex & $\begin{array}{l}\text { Upper } \\
\operatorname{limb}\end{array}$ & $\begin{array}{l}\text { Lower } \\
\text { limb }\end{array}$ & $\begin{array}{c}\text { Clinical } \\
\text { assessment: } \\
\text { symmetrical } \\
\text { (S) or } \\
\text { asymmetrical (A) }\end{array}$ \\
\hline 1 & $F$ & & & A \\
\hline 2 & $\mathrm{M}$ & 0.50 & 0.89 & S \\
\hline 3 & $\mathrm{~F}$ & 0.26 & 0.53 & $\mathrm{~S}$ \\
\hline 4 & M & -0.17 & 0.00 & A \\
\hline 5 & $\mathrm{~F}$ & 0.35 & 0.41 & $S$ \\
\hline 6 & $\mathrm{~F}$ & -1.04 & -0.21 & $\mathrm{~A}$ \\
\hline 7 & $\mathrm{~F}$ & -0.83 & -1.00 & A \\
\hline 8 & $\mathrm{~F}$ & -0.46 & 0.00 & $\mathrm{~S}$ \\
\hline 9 & $\mathrm{M}$ & 0.71 & 6.12 & A \\
\hline 10 & $\mathrm{~F}$ & 0.58 & -1.17 & A \\
\hline 11 & $\mathrm{~F}$ & -0.09 & -0.38 & S \\
\hline 12 & $\mathrm{~F}$ & & & A \\
\hline 13 & $\mathrm{M}$ & 0.75 & 0.17 & $S$ \\
\hline 14 & $\mathrm{M}$ & 0.26 & -0.25 & $S$ \\
\hline 15 & $\mathrm{~F}$ & 0.25 & -0.13 & $S$ \\
\hline 16 & M & -0.29 & 0.08 & $\mathrm{~S}$ \\
\hline 17 & $\mathrm{~F}$ & -0.83 & -0.04 & $\mathrm{~S}$ \\
\hline 18 & M & 0.05 & 0.51 & $\mathrm{~S}$ \\
\hline 19 & $M$ & -1.34 & 0.01 & A \\
\hline 20 & $M$ & -0.21 & 0.04 & $S$ \\
\hline 21 & $M$ & 0.54 & -0.09 & $\mathrm{~S}$ \\
\hline 22 & M & 0.75 & -0.46 & $S$ \\
\hline 23 & $M$ & -1.16 & 0.03 & A \\
\hline 24 & $M$ & 0.83 & 0.00 & A \\
\hline 25 & $M$ & 0.00 & 0.04 & S \\
\hline 26 & $F$ & 2.25 & 0.12 & A \\
\hline 27 & $\mathrm{~F}$ & 0.09 & 0.39 & $S$ \\
\hline 28 & M & -0.12 & -0.04 & S \\
\hline 29 & M & 0.42 & 1.25 & A \\
\hline 30 & $\mathrm{~F}$ & 0.46 & -0.33 & $\mathrm{~S}$ \\
\hline 31 & $\mathrm{~F}$ & -1.67 & -3.33 & A \\
\hline 32 & $F$ & 0.33 & 0.08 & $\mathrm{~S}$ \\
\hline 33 & $M$ & & & $\mathrm{~S}$ \\
\hline 34 & $M$ & -1.00 & -0.17 & $\mathrm{~A}$ \\
\hline 35 & $\mathrm{~F}$ & 0.08 & 0.33 & S \\
\hline 36 & $M$ & -0.50 & -0.21 & $\mathrm{~S}$ \\
\hline 37 & $M$ & 2.46 & 0.54 & A \\
\hline 38 & $M$ & -1.00 & -0.96 & $\mathrm{~A}$ \\
\hline 39 & $\mathrm{M}$ & -0.88 & 0.42 & $\mathrm{~S}$ \\
\hline
\end{tabular}

${ }^{1}$ In normal children differences are less than $1 \mathrm{~cm}$.

height for stature was much below that of other patients, with SD score decreasing from -2.0 at age 5.9 to -3.3 at age 10.4, had the second greatest asymmetry of the legs among the 39. Stature is measured using the longer limb, so this may be additional evidence that the longer limb was hypertrophied, rather than the shorter atrophied. Indeed the five patients with one leg significantly longer than the other had SD scores of sitting height for stature at referral of $-2.6,-1.2,-1.1$, and 0.6 , averaging -1.3 , which is well below that of the remainder of the patients.

\section{HEAD SIZE, INTELLIGENCE, AND EDUCATION}

The facial appearance of the child with Silver-Russell syndrome is characteristic. Illustrations have been given by Tanner and $\mathrm{Ham}$ (44), among others. The face itself is small and triangular and appears to be surmounted by a high bossed forehead. This craniofacial disproportion occasionally leads to a misdiagnosis of hydrocephalus (40).

Although it is clear that the face, and particularly the mandible, is smaller than normal, the head circumference has been variously described as within normal limits $(17,31)$ or small $(29,37,38)$. We have measured the head circumference in 37 of our cases, and in Figures 13 and 14 the results of the first occasion on which the measurements was done for each child are plotted on current British standards (42). On average the patients were smaller than normal subjects; the mean SD score was $-1.88 \pm 0.28$ units, with no significant difference according to sex or symmetry. Although

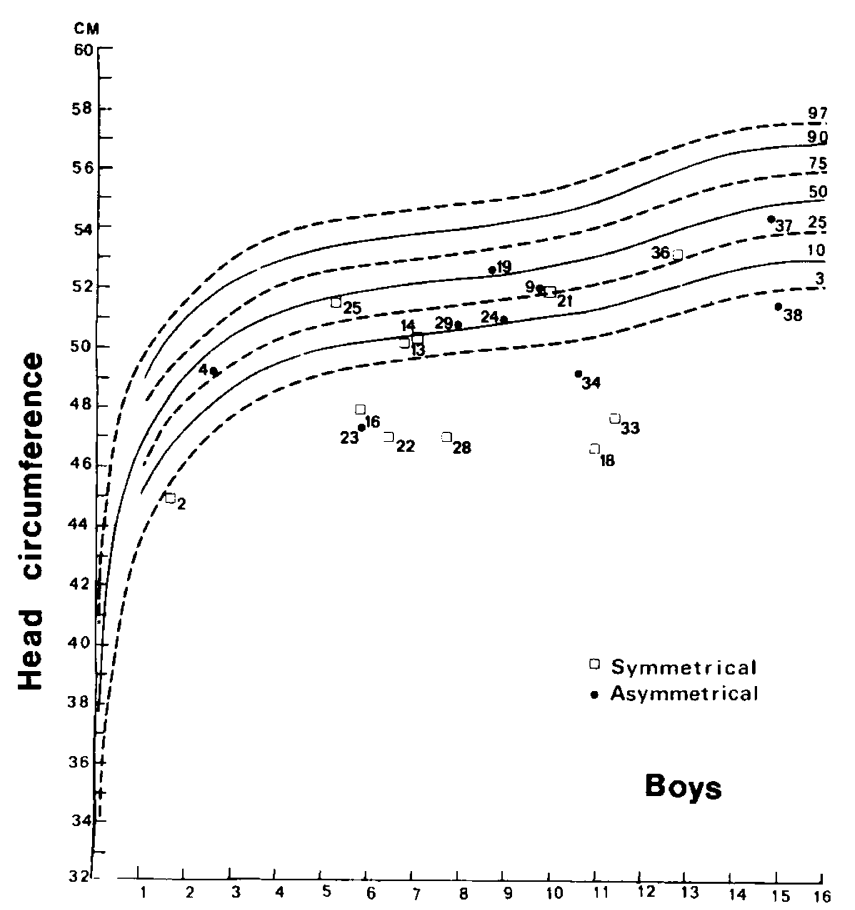

Age, years

Fig. 13. Head circumference in 20 boys with Silver-Russell syndrome. , asymmetrical patients: $\square$, symmetrical.

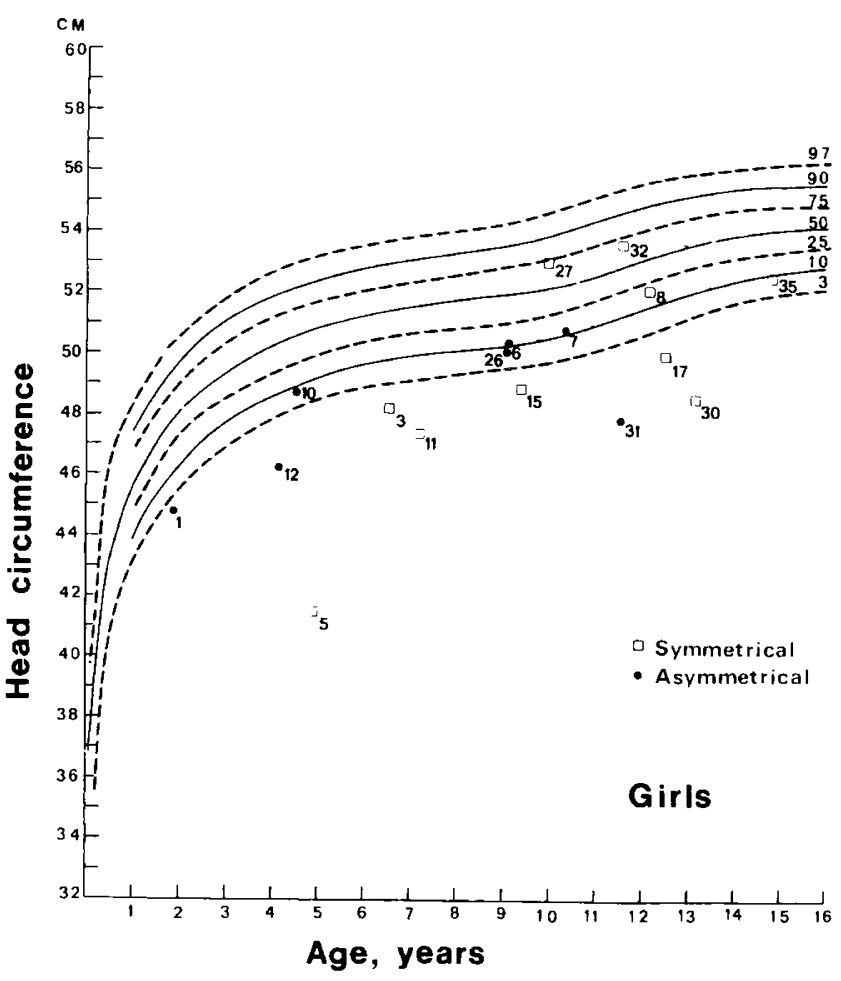

Fig. 14. Head circumference in 17 girls with Silver-Russell syndrome. , asymmetrical patients: $\square$, symmetrical. 
about half of the patients fell within normal limits, nine boys and nine girls were below the 3rd percentile, some of them far below. About a third of the 29 cases we found in the literature were also below the 3 rd percentile with a frequency distribution similar to ours. Fifteen of our 18 children with head circumferences below the 3 rd percentile were at normal schools and three at schools for educationally subnormal children (usually IQ less than 80). All 19 children with head circumferences above the 3 rd percentile whose school is known were at normal schools; the difference in incidence of educational subnormality is not statistically significant. Incidence of pregnancy complications was not significantly greater in those with small head circumference than in others.

On average, the stunting of height was greater than that of head circumference. The correlation coefficient between head circumference SD score and height SD score on the same occasion was only 0.25 which for 37 cases does not reach the $10 \%$ level of significance. The correlation between head circumference SD score and birth weight SD score was -0.19 .

Formal IQs were available for 11 children. The mean was 103.4 with an SD of 21 and a range from 70 to 130 . Evidently the great majority of these children were of normal intelligence despite their reduced head circumference and general size.

\section{SUBCUTANEOUS FAT GROWTH}

In terms of the standards of Tanner and Whitehouse (46), 32 of the children at first referral were below the 50 th percentile for triceps skinfold and 14 of these were below the 3 rd percentile. For subscapular skinfolds, 28 were below the 50 th percentile. By the time of the latest visit, an average of 6 years later, the skinfolds values had risen somewhat. Figure 15 shows the SD score for triceps (using the log transform) at each year of age. The correlation between changes in height SD score and triceps skinfold SD score between the first and last visit was only 0.32 , so gain of skinfold is a limited guide to increase in height.

Seven of our patients were amongst those whose fat cell number and fat cell size were studied at first referral by Brook (5) in gluteal needle biopsy samples. The number of cells was markedly reduced in all, with an average SD score of -2.2 , and a range of -1.0 to $-3.2 \mathrm{U}$. The triceps skinfold SD score in the same cases averaged $-1.26 \pm 0.42$.

The administration of $\mathrm{HGH}$ had no noticeable effect on the skinfold in these patients (47), this being in marked contrast to the sharp loss of fat it causes in patients with growth hormone deficiency.

\section{BODY WEIGHT}

At first referral 35 of the children were below the 3 rd percentile for weight and the average SD score was $-3.3 \pm 0.17$. At the last visit their average $\mathrm{SD}$ score was $-2.09 \pm 0.12$. At that time five children were at the 10 th-25th percentiles, 11 at the 3 rd- -10 th percentiles, and 23 still below the 3 rd percentile.

\section{DISCUSSION}

The main questions upon which our data may throw light are: (1) whether Silver-Russell syndrome constitutes an entity clearly separable from the general run of light for dates (LFD) infants with no obvious syndrome diagnosis; (2) if so, whether the syndromes of Silver and Russell should be held separate or combined together: (3) what may be expected as to prognosis, both for height and for intelligence: $(4)$ whether puberty is normal or abnormal; (5) questions of aetiology and treatment. These will be discussed in order.

\section{SILVER-RUSSELL SYNDROME AS AN ENTITY}

The problem is whether the Silver-Russell patients are simply those LFD children who turn out smallest in childhood, that is, have a later height below $2 \mathrm{SD}$. The mean height SD score of our cases at referral was -3.6 with a range of -2.2 to -6.3 , so they would have to represent the very far end of a very long tail. However, that might not be impossible.

Fitzhardinge and Steven (15) showed that a group of LFD infants followed each year to age 6 had height curves which were similar to those of our patients, that is, parallel to the standards but below them. At 6 years $35 \%$ were at or below the 3 rd percentile. Babson (1) and Brandt (4) found the same. If, for example, LFD babies averaged 1.0 SD below the population mean and had the normal variation, then their $95 \%$ range would be from +1.0 SD to $-3.0 \mathrm{SD}$ and there would be a few per thousand in the -3.0 to -4.0 SD range. To obtain our figures, however, we would have to sample an improbably large population of LFD infants.

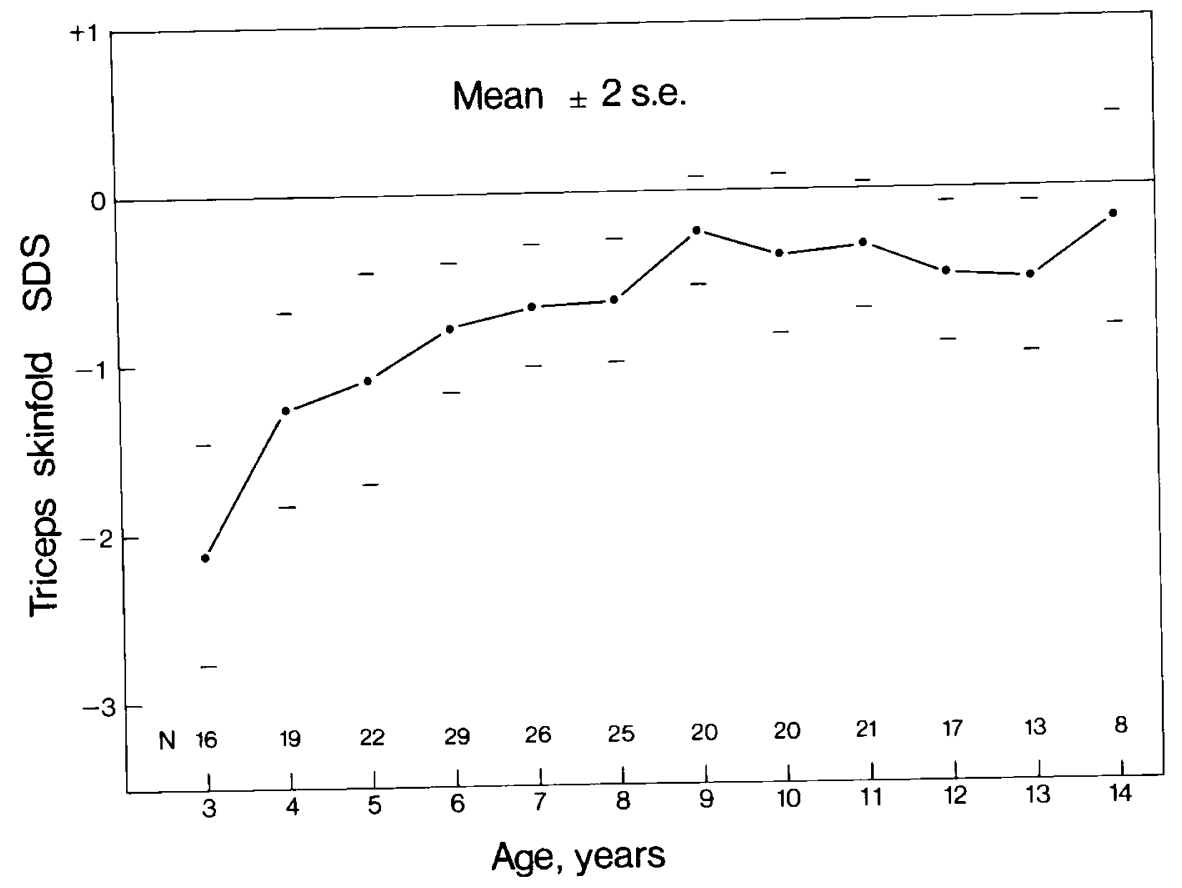

Fig. 15. Triceps skinfold transform SD scores $(S D S)$ at ages 3-13. Twenty-six children, mixed longitudinal, numbers at each age as shown (sexes combined). 
The facial appearance of the Silver-Russell child does seem distinctive and perhaps different from that of the usual run of LFD children, but this is not certain.

One point does argue against Silver-Russell cases as the tail of the LFD range. Numerous authors (e.g., Ounsted and Ounsted (27)) have shown that birth weight is a quantitatively inherited characteristic and that the usual LFD children have an excessive number of LFD sibs. We have demonstrated that this is not the case in Silver-Russell syndrome. Only 2 of the 61 sibs of our cases had an adjusted birth weight below 2 SD, which accords with statistical expectation for the normal population. This seems to us a rather powerful argument in favor of the Silver-Russell syndrome as a distinct entity.

We may also be missing cases of the syndrome. The birth weights of the children we studied were all below $2 \mathrm{SD}$, as a condition of diagnosis. However, when we plotted the frequency distribution of adjusted birth weights it looked as though we had a fundamentally Gaussian curve with a cut-off at $-2.0 \mathrm{SD}$ and a missing right-hand tail amounting to some $10 \%$ of cases. These would have had birth weight SD scores between -1.5 and -2.0 . It is possible that the diagnosis, in principle at least, should be extended to include such patients. Indeed in an earlier paper, Tanner and Ham (44) deliberately included one such child who had the typical Silver-Russell facial appearance. Silver and Gruskay (36) also included as an example of the syndrome an asymmetric child of short stature whose birth weight was at the 15 th percentile.

The distribution of height at first referral also seemed Gaussian but without any cut-off; the upper tail extended to -2.2 SD. Thus there seem to be no cases excluded by the criteria of $<2 \mathrm{SD}$, unless some of the possible cases of birth weight -1.5 to -2.0 SD score later have heights in the same range. If so, there would be no way of diagnosing them (except for the very subjective facial appearance) and perhaps no point in doing so. In our cases, however, status in height (at age 6) and in birth weight were not significantly correlated $(r=-0.10)$.

\section{SILVER AND RUSSELL VERSUS SILVER-RUSSELL}

Much discussion has taken place about whether to distinguish the Silver from the Russell syndrome on the grounds that the former patients have a noticeable asymmetry of limbs or trunk and the latter do not. When we measured the degree of limb asymmetry by photogrammetry and plotted all of the cases together we found no evidence of the bimodal distribution the theory proposes. Thus we think no real distinction should be made on the grounds of symmetry and all cases should be called Silver-Russell syndrome. However, the distribution of right-left difference in limb length was much wider than that seen in normal children; it seems that the processes which normally restrict the range of asymmetry in normal subjects are not fully effective in Silver-Russell syndrome.

There has also been discussion as to whether the limb asymmetry is caused by one side being hypoplastic or the other hypertrophied. By comparing the lower limbs with the upper and each with the trunk length we have indications that the longer of the two limbs is usually the abnormal one and thus hypertrophied relative to the remainder of the body.

\section{PROGNOSIS}

The course of growth of the 39 children we have studied followed a fairly standard pattern. We have no data on length at birth, but height at initial referral (average age 4.6 years) was on average 3.6 $\mathrm{SD}$ below the mean. This situation changed little during the next 10 years; the height curves followed the normal pattern, but at a level substantially below the normal range. Height velocity averaged about the 30th percentile. At puberty, in the few cases we have seen, there was an adolescent height spurt also around the 30 th percentile. Thus we would expect these children to be small as adults. We have as yet followed few to adulthood; these few bear out our expectation. Assuming the height prediction equations developed for normal children (48) apply to Silver-Russell patients we predicted a mean adult height of $-2.9 \mathrm{SD}$ for the 20 cases for whom the prediction can be made.

This result agrees with the finding that only a small element of retardation, or growth delay, is present in these patients. Bone age at referral averaged $70 \%$ of chronologic age, and was retarded beyond normal limits in only $30 \%$ of cases. Thus we would not expect these children to catch up very much towards normal. In this they differ entirely from the small children who are simply retarded in growth, whom we diagnose as "small/delay" (42).

Some authors (e.g., Ounsted and Ounsted (28)) write of "growth-retarded" children when they mean those of small size, and even of "growth-accelerated" children when they mean large. This terminology produces the same confusion as did the use of the word "premature" for "low birth weight." Figure 16 shows a composite graph of height growth in Silver-Russell syndrome, Turner's syndrome, true isolated growth hormone deficiency (both untreated), and children with the diagnosis of small/delay. Small/ delay children catch up (not to the 50 th percentile on average, since they are usually born to short parents). But the Silver-Russell children do not, since delay is only a small and relatively unimportant factor in their small size.

Our findings indicate that the extreme leanness seen in most cases in infancy is somewhat ameliorated during growth, although when last seen, only a third reached the 3rd percentile for skinfolds. Weight also improved somewhat, although only from an average SD score of $-3.3 \mathrm{U}$ at first visit to $-2.1 \mathrm{U}$ at the last.

Head circumference was less affected than other body measurements, two-thirds of the patients being within normal limits. Growth of head circumference is governed by factors considerably different from those governing the rest of the body, and its timing is quite different (41). It is not surprising, therefore, that the SD score for head circumference in these patients is not significantly correlated either with SD score for height or for birth weight. Three of the 18 children with circumferences below the 3 rd percentile were educationally subnormal, but this proportion did

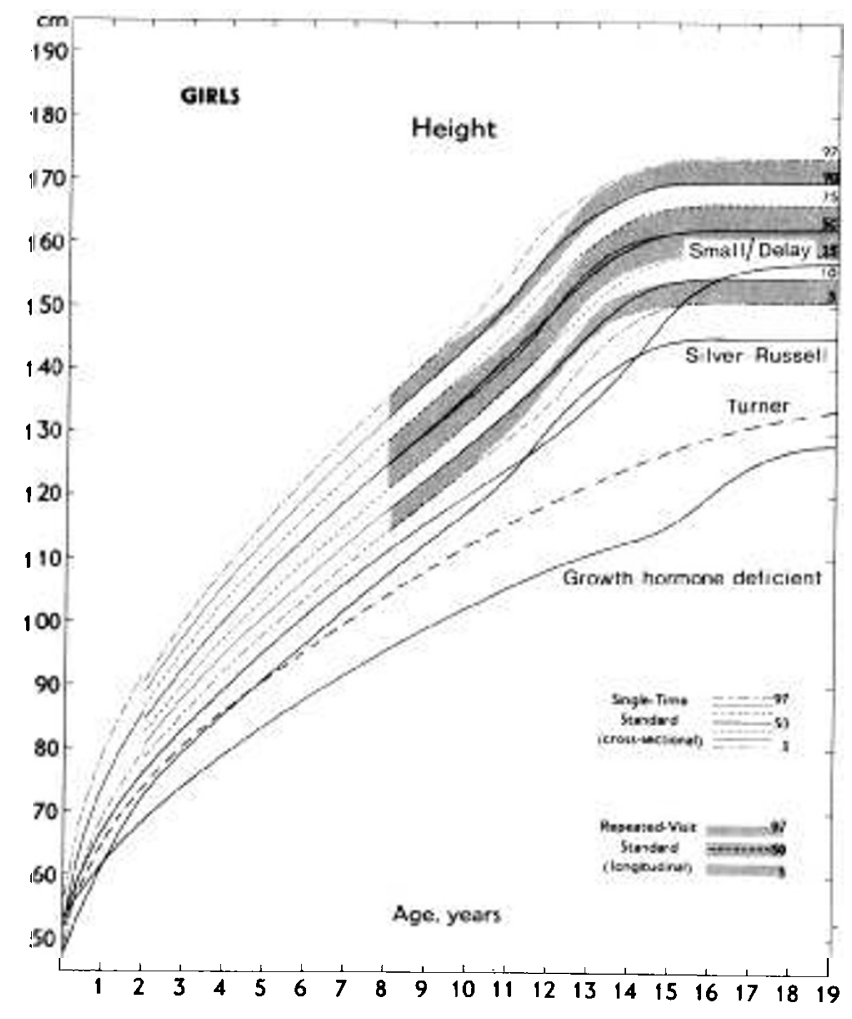

Fig. 16. Composite graphs of height growth in Silver-Russell syndrome, untreated Turner's syndrome, small/delay, and untreated isolated growth hormone deficiency. 
not differ significantly from a chance assortment of the cases. The majority were of normal educability and the patients for whom IQs had been tested averaged 103. The intellectual development of LFD children depends on multiple factors in addition to the low birth weight itself. Babson and Kangas (2), in a sample of 43 low birth weight children without congenital malformations or fetal diseases (rubella, etc.), found no significant difference in IQ from normal subjects at 4 years of age. Drillien (11) has stressed the importance of social factors, finding that LFD children in less well-off homes at 10-12 years had IQs 9 points below control subjects, whereas those in well-off homes equalled the performance of children of normal birth weight.

\section{PUBERTY}

Despite early claims to the contrary, it seems clear that these children have a perfectly normal pubertal development. By our current standards one developed a little late and one a little early, but there is no reason to suppose that any real pathology of sexual development occurs. In previously published cases of SilverRussell syndrome we found only seven with reported manifestations of puberty $(27,35,39,40,26)$. Six of these fell within normal limits, one only being early: and even this case, with menarche at 9.5 years, is not in the clearly pathologic range. Urinary gonadotrophin levels were not done on our patients. The older reports of elevated levels used questionable methods and it seems improbable that any abnormality will be found with modern techniques.

\section{ETIOLOGY AND TREATMENT}

We have one useful piece of information to contribute as far as etiology is concerned. The condition is not familial, at least in the vast majority of cases. An occasional familial incidence has been suggested by two reports in which sibs were affected $(8,16)$. Rimoin (30) described the syndrome in a pair of identical twins: Silver (35) in one twin only in two pairs, one like- and one opposite-sexed. Pregnancy is apparently normal in the majority of cases, as is length of gestation and labor. Maternal age and height are normal. It seems most likely that the fault in development arises at an early stage, although whether because of intrinsic faults or extrinsic factors is unknown.

Treatment with $\mathrm{HGH}$ has been given to 19 cases for 1 year but with no significant effect. All had normal growth hormone levels on stimulation, so perhaps this is to be expected.

\section{SUMMARY}

1. The growth of 39 children with Silver-Russell syndrome has been followed for periods of $1-13$ years. All children were below 2 SD score in birth weight and in height in later childhood, and had the characteristic facial features and no other demonstrable pathology. Measurements taken regularly included height, sitting height, weight, skinfolds, head circumference, limb lengths by photogrammetry, and bone age by hand-wrist radiograph.

2. The average birth weight, adjusted for sex, length of gestation, and birth order was 3.1 SD below the mean. The distribution of birth weights was unimodal and approximately Gaussian, with a cut-off at $-2 \mathrm{SD}$, corresponding to the criterion for diagnosis. It is suggested that some $10 \%$ of cases have birth weights in the -1.5 to $-2.0 \mathrm{SD}$ range.

3. The incidence of abnormalities during pregnancy or labor was no greater than in normal children. The length of gestation was normal, as were maternal age and height.

4. There was no case of Silver-Russell syndrome among the 61 siblings. The birth weight mean and distribution of the sibs were no different from those of the reference population.

5. Height at first referral (at average age 4.6 years) had a mean of -3.6 SD scores. This figure changed little during the period of follow-up; at age 13 mean height was -3.4 SD score. Prediction of adult height from height and bone age at age 7 for the 20 cases available gave an SD score averaging -2.9 . Height velocity was within normal limits in all cases, but averaged about the 30th percentile. There was no significant correlation between height and birth weight SD score.

6. Bone age at first referral was on average $69 \%$ of chronologic age, with 13 of 39 patients below the conventional limits of normal. Subsequently, however, bone age increased faster than chronologic age and by puberty, on the average, it was $95 \%$ of chronologic age. that is about 6 months' retarded.

7. Nineteen cases were treated with $\mathrm{HGH}$ for a year. Although an initial increase in height velocity occurred in some cases it was followed by a compensatory deceleration in the post-treatment year, when treatment stopped, so there was ultimately no gain.

8. Contrary to some earlier reports in the literature, puberty occurred normally in these children, both in regard to the timing of the various stages and the amount of the adolescent growth spurt.

9. Asymmetry of the arms and legs was found to exceed the limits of normal in all cases clinically diagnosed as Silver syndrome, and not to exceed these limits in those diagnosed as Russell syndrome. However, the distribution of the right-left differences over all cases was unimodal, with a mean of 0 but much greater variation than in normal subjects. We believe that asymmetry is a quantitative character only and Silver and Russell cases represent the same syndrome.

10. Head circumference averaged 1.9 SD below the mean for age and sex: there was no correlation with height or birth weight. Half of the children were within normal limits. Three children of the 39 were educationally subnormal but the average IQ in the 11 other cases tested was 103 .

11. Triceps and subscapular skinfolds were below the 50th percentile in 32 and 28 of 39 cases, respectively at referral; the mean SD score for triceps transform was $-1.4 \mathrm{U}$. There was a gain to -0.4 during follow-up. The administration of $\mathrm{HGH}$ had no effect on skinfold values. Body weight SD score was -3.3 at first referral and -2.1 on last visit.

12. The question as to whether these children represent a specific syndrome or constitute the lower end of the distribution of all LFD children (that is, those selected for low height in childhood) remains unresolved; but reasons are given for thinking that the former alternative is probably correct.

\section{REFERENCES AND NOTES}

1. Babson. S. G.: Growth of low birthweight infants. J. Pediat., 77: 11 (1970)

2. Babson, S. G., and Kangas, J.: Pre-school intelligence of undersized term infants. Amer. J. Dis. Child., 117: 553 (1969).

3. Black J : Low birthweight dwarfism. Arch. Dis. Childhood, 36: 663 (1961). circumference of low birthweight infants until 18 months. Proceedings of Centre Internationale de l'Enfance Réunion de Co-ordination, London, 1972. International Children's Centre, Paris, 1973.

5. Brook C G. D. Evidence for a sensitive period in adipose cell replication in man. Lancet. ii: 624 (1972).

6. Butler, N. R., and Alberman, E. D.: Perinatal Problems (Livingstone, Edinburgh, 1969 ).

7. Butler N. R and Bonham, D. G.: The British Perinatal Mortality Survey (Livingstone, Edinburgh, 1963).

8. Callaghan, K. A.: Asymmetrical dwarfism or Silver's syndrome in two male siblings. Med. J. Aust., 2: 789 (1970)

9. Chalkley, S. R., and Tanner, J. M.: Incidence and effects on growth of antibodies to human growth hormone. Arch. Dis. Childhood, 46: 160 (1971).

10. Curi, J. F. J., Vanucci, R. C., Grossman, H., and New, M.: Elevated serum gonadotrophins in Silver's syndrome. Amer. J. Dis. Child., 114: 658 (1967).

11. Drillien. C. M.: The growth and development of the prematurely born infant (Livingstone, Edinburgh. 1964)

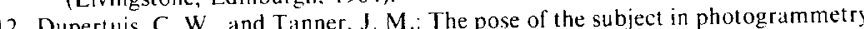
and somatotyping. Amer. J. Phys. Anthropol. N. S., 8: 27 (1950).

3. Ferrier, P., Shepard, T. H., and Knapp-Smith, E.: Growth disturbances and values for hormone excretion in various forms of sexual development. Pediatrics, 28: 258 (1961)

14. Fitch, N., and Pinsky, L.: The lateral facial profile of the Silver-Russell dwarf. $J$ Pediat., 80: 827 (1972).

15. Fitzhardinge, P. M., and Steven, E. M.: The small for date infant. I. Later growth patterns. Pediatrics, 49:67! (1972)

16. Fuleihun, D. S. Des Kaloustian V M and Najjar, S. S.: The Russell-Silver syndrome: Report on three siblings. J. Pediat., 78: 654 (1971).

17. Gareis, F. J., Smith, D. W., and Summitt, R. L.: The Russell-Silver syndrome without asymmetry. J. Pediat., 79: 779 (1971) 
18. Girard, J., and Kaufmann, H. J.: Der Russell-Zwerg. Monatsschr. Kinderheilk., 113: $696(1965)$.

19. Giuntini, R.. and Cabras, G.: Etiopatogenetic observations on a case of "intrauterine nanism." Russell syndrome. Minerva Ortoped., 13: 20 (1958).

20. Haslam, R. M., Berman, W.. and Heller. R.: Renal abnormalities in the Russell-Silver syndrome. Pediatrics, 51: 216 (1973).

21. Holden, J. D.: The Russell-Silver dwarf. Develop. Med. Child Neurol., 9: 457 (1967).

22. Jeune, M.. Bethenod, M., Freycon, F., Nivelon, J. L., Racle, P., and Michel, M. Deux cas de nanisme intrauterine de type Russell-Silver. Pediatrie, 20:301 (1965).

23. Marshall, W. A., and Harrison, J. M.: Normal standards for the relationships between the lengths of limbs and of limb segments in young British men: A photogrammetric study. Human Biol., 43: 526 (1971).

24. Marshall, W. A., and Tanner, J. M.: Variations in the pattern of pubertal changes in girls. Arch. Dis. Childhood, 44: 291 (1969).

25. Marshall, W. A., and Tanner, J. M.: Variations in the pattern of pubertal changes in boys. Arch. Dis. Childhood, 45: 193 (1970).

26. McDowell, and Sproles, E. T.: Russell-Silver syndrome, a nine-year follow-up. Amer. J. Dis. Child. 126: 794 (1973).

27. Moseley, J. E., Moloshol, R. E., and Freiberger, R. H.: The Silver syndrome: Congenital asymmetry, short stature and variations in sexual developmentRoentgen features. Amer. J. Roentgenol., 97: 4 (1966).

28. Ounsted, M., and Ounsted, C.: On foetal growth rate. (Heinnemann, London, 1973).

29. Reister, H. C... and Scherz, H. G.: Silver syndrome--A report of two cases and a review of the literature. Amer. J. Dis. Child., 107: 410 (1964).

30. Rimoin, D. L.: The Silvers syndrome in twins: Birth defects Orig. Art Ser. 183 (1969).

31. Roget, J., Beaddoin, A., and Guilhot, J.: Un cas d'hemihypertrophie congénitale avec aspects normal des cisternes de la base du crâne. Pediatrie, 10: 195 (1955).

32. Rossier, A.: Intrauterine nanism with mandibular craniofacial , 10 : 195 (1955). franc ', Pediat., 19:561 (1962).

33. Russell, A.: A syndrome of intrauterine dwarfism recognisable at birth with craniofacial dysostosis, disproportionately short arms and other abnormalities (5 examples). Proc. Royal Soc. Med., 47: 1070 (1954).

34. Silver, H. K.: Congenital asymmetry, short stature and elevated urinary gonadotrophins. Amer. J. Dis. Child., 97: 968 (1959).

35. Silver, H. K.: Asymmetry, short stature and variations of sexual development: A syndrome of congenital malformation. Amer. J. Dis. Child., 107: 495 (1964).

36. Silver, H. K., and Gruskay, F. L.: Syndrome of congenital and hemihypertrophy and elevated gonadotrophins. Amer. J. Dis. Child., 93: 559 (1957).

37. Silver, H. K.. Kiyasu, N., George, J., and Deamer, W. C.: Syndrome of congenital hemihypertrophy, shortness of stature and elevated urinary gonadotrophins. Pediatrics, /2: 368 (1953).

38. Snow, R., Sacks, M., and Cornblath, N.: Ketotic hyperglycemia in a Russell dwarf. J. Pediat., 69: 121 (1966).

39. Stool, S., and Cohen, P.: Silver's syndrome: Syndrome of congenital asymmetry, short stature and altered patterns of sexual development. Amer. J. Dis. Child. 105: 199 (1963) 40. Szalay, G. C.: Pseudohydrocephalus in dwarfs: The Russelt dwarf. J. Pediat., 63:
622 (1963).
41. Tanner, J. M.: Growth at Adolescence, Ed. 2 (Blackwell Scientific Publications, Oxford, 1962).

42. Tanner, J. M.: Physical growth and development. In: J. O. Forfar and G. C. Arneill: Textbook of Paediatrics (Churchill, Livingstone, London, 1973).

43. Tanner, J. M.: Growth and endocrinology of the adolescent. In: L. 1. Gardner: Endocrine and Genetic Disease in Childhood, Ed. 2 (Saunders, Philadelphia. 1975).

44. Tanner, J. M., and Ham, T. J.: Low birthweight dwarfism with asymmetry (Silver's syndrome)-Treatment with human growth hormone. Arch. Dis. Childhood, 44: 231 (1969).

45. Tanner, J. M., and Thomson, A. M.: Standards for birthweight at gestation periods from 32 to 42 weeks allowing for maternal height and weight. Arch. Dis. Childhood, 45: 566 (1970).

46. Tanner, J. M., and Whitehouse, R. H.: Standards for subcutaneous fat in British children. Brit. Med. J., I: 446 (1962).

47. Tanner, J. M., Whitehouse, R. H., Hughes, P. C. R., and Vince, F. P. Effect of human growth hormone treatment for I to 7 years on growth of 100 children. with growth hormone deficiency, low birthweight, inherited smallness, Turner's syndrome and other complaints. Arch. Dis. Childhood, 46: 745 (1971).

48. Tanner, J. M., Whitehouse, R. H., Marshall, W. A., and Carter, B. S.: Prediction of adult height from height, bone age and occurrence of menarche at ages 4 to 16 with allowance for midparent height. Arch. Dis. Childhood, 50: 14 (1975)

49. Tanner, J. M., Whitehouse, R. H.. Marshall, W. A.. Healy, M. J. R., and Goldstein, H.: Assessment of Skeletal Maturity and Prediction of Adul Height: TW2 Method (Academic Press, London, 1975).

50. Tanner, J. M., Whitehouse, R. H., and Takaishi. M.: Standards from birth to maturity for height, weight, height velocity and weight velocity: British children, 1965. Arch. Dis. Childhood, 41: 454, 613 (1966)

51. Thomson, A. M., Billewicz, W. Z., and Hyten, F. E.: Obstet. Gynecol Brit. Commonw., 75: 903 (1968)

52. Tulinuis, H., Tryggvanson, K., and Hauksdottir, H.: 45.X/46.XY chromosome mosaic with features of the Russell-Silver syndrome: A case report with a review of the literature. Develop. Med. Child Neurol., 14: 161 (1972).

53. Warkany, J., Monroe, B. B., and Sutherland, B. S.: Intrauterine growth retardation. Amer. J. Dis. Children, 102: 249 (1961).

54. Zachmann, M., Prader, A., Kind, H. P., Haflinger, H., and Budlinger, H.: Testicular volume during adolescence. Helv. Paed. Actal 29: 61 (1974).

55. We wish to thank Mr. R. H. Whitehouse, Mr. P. C. R. Hughes, and Mr. M. Nowak for the measurements and bone ages; $M$ iss Janet Baines for assembling much of the data; Dr. W. A. Marshall and Dr. C. G. D. Brook for helpful criticism of the manuscript; and Drs. H. Barrie, J. Colley, P. Davies, G. Day, P. R. Evans, H. Halsall, K. Holt, J. Luder. G. H. Newns, A. P. Norman, I. C. S. Normand, J. D. Roscoe, J. Rubie, D. Savage, L. Scott, M. N. Smith, J. Trowell, R. Wigglesworth, and M. Yerbury and Professor R. Fraser for referring patients. We acknowledge gratefully the financial support of the British Council and the Medical Research Council.

56. Dr. H. Lejarraga is a British Council Scholar. Present address: Hospital de Ninos, Buenos Aires, Argentina.

57. Requests for reprints should be addressed to: J. M. Tanner, M.D., Department of Growth and Development, Institute of Child Health, 30 Guilford St.. London WCIN IEH (England).

58. Accepted for publication April 2, 1975. 